CERE Working Paper, 2021:2

\title{
Teleworking from a near-home shared office in Mexico City -A discrete choice experiment on office workers
}

\author{
Jose Alberto Lara-Pulido and Adan L. Martinez-Cruz
}

The Centre for Environmental and Resource Economics (CERE) is an inter-disciplinary and inter-university research centre at the Umeå Campus: Umeå University and the Swedish University of Agricultural Sciences. The main objectives with the Centre are to tie together research groups at the different departments and universities; provide seminars and workshops within the field of environmental \& resource economics and management; and constitute a platform for a creative and strong research environment within the field.

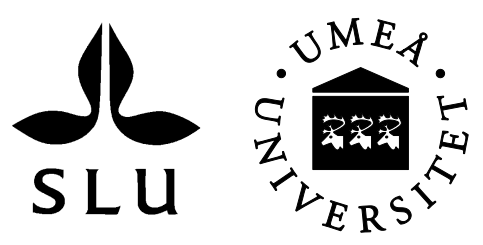




\title{
Teleworking from a near-home shared office in Mexico City - A discrete choice experiment on office workers
}

\author{
Jose Alberto Lara-Pulido ${ }^{a}$ \\ ${ }^{a}$ Centro Transdisciplinar Universitario para la Sustentabilidad (CENTRUS) \\ Universidad Iberoamericana, Mexico \\ jose.lara@ibero.mx
}

\author{
Adan L. Martinez-Cruz ${ }^{b, c, *}$ \\ ${ }^{b}$ Department of Forest Economics and \\ Centre for Environmental and Resource Economics (CERE), \\ Swedish University of Agricultural Sciences (SLU), Sweden \\ ${ }^{c}$ Department of Economics, \\ Centro de Investigacion y Docencia Economicas (CIDE), Mexico \\ adan.martinez.cruz@slu.se \\ * Corresponding author
}

January 10, 2021

\begin{abstract}
Teleworking from home during the COVID-19 pandemic has faced challenges specific to cities of emerging economies - e.g. lack of access to internet. This paper points out that these challenges may be overcome if teleworking is performed from a shared office located within reasonable commuting time from a worker's home. In November and December 2019, a sample of office workers in Mexico City was presented to a discrete choice experiment (DCE) describing alternatives under which they may choose teleworking two days a week from a shared office. Commuting time to shared offices is an attribute taking four values - within 15 minutes, 30 minutes, 45 minutes, or 60 minutes walking distance from a worker's home. Availability of spaces to park bikes is another attribute. The price attribute is described as the amount that would be cut from worker's monthly paycheck. Based on random parameter logit specifications, willingness to pay (WTP) for teleworking from a shared office two days a week is estimated at (2019) MXP 1,460 (USD 76.68) on a monthly basis. Average value of one-hour of commuting time is estimated at MXP 73.75 (USD 3.87). Average WTP for bike parking is MXP 280 (USD 14.07) on a monthly basis.
\end{abstract}

Keywords: Teleworking; near-home shared office; value of commuting time; bike parking; discrete choice experiment; Mexico City.

JEL Classification: R00, R39, R41 


\section{Introduction}

Commuting in Mexico City (CDMX) is expensive. Transportation costs can consume up to a third of a salary of a minimum-wage worker (Guerra, 2017), and as much as $40 \%$ of an annual middle-income class salary (Arredondo, 2017). The majority of work-related trips cover at least $15 \mathrm{kms}$ (Graizbord, 2015). Time-wise, commuting by car in 2019 wasted 195 hours when driving in rush hours (TomTom, 2020). Unfortunately, this characterization, with minor differences, applies to other megacities - e.g. New Delhi, Sao Paulo, Manila, Nairobi, and Accra (see Hess \& Narteh-Yoe, 2020).

Teleworking may reduce average commuting times by reducing work-related trips and, in turn, alleviating congestion during peak hours (Zhang et al., 2020). Teleworking refers to work arrangements under which an employee performs duties and responsibilities of his/her position, and other authorized activities, at an approved (by his/her employer) location other than his/her employer's premises (USOPM, 2020). The emergence of mobile devices such as laptops and mobile phones has enabled employees to work from practically any location they need to work, but teleworking arrangements most commonly involve working from home (López-Igual \& Rodríguez-Modroño, 2020).

Leaving COVID-19 conditions aside, teleworking from home has not spread as much as expected despite being a technically feasible option since at least a couple of decades in Europe and USA. In practice, a number of reasons have made teleworking from home an arrangement to which most office workers have not realistically had access to - either due to conditions related to employees characteristics, or due to employers' unwillingness to shift managerial practices, or both (Aguilera et al., 2016; Bojovic et al., 2020; Chang, 2019; López-Igual \& Rodríguez-Modroño, 2020; Zhang et al. 2020). In addition, teleworking from home conveys risks such as emotional isolation, and loss in productivity (ILO, 2020).

Before the COVID-19 pandemic, office workers in emerging economies had little experience with teleworking from home. With COVID-19 lockdown implemented worldwide, it has promptly been documented that people in emerging economies face additional challenges than their peers in developed economies when trying to telework from home. In CDMX, for instance, most people have access to internet service but its quality imposes a challenge to optimally perform job-related tasks. Overcrowded living conditions in CDMX also represent a barrier to teleworking from home - not to mention the more than proportional burden faced by women that have teleworked from home during the COVID-19 pandemic (Arellano García, 2020; Mendoza Rojas, 2020; Monroy-Gómez-Franco, 2020; Vázquez, 2020).

This study starts by highlighting that many challenges of teleworking from home may be overcome if, instead, people telework from a shared office. For instance, by providing an out-of-home space that allows a clear division between personal and work domains, a shared office may contribute to reaching a healthy work-life balance. Also, a shared office provides conditions that a person living in an overcrowded dwelling can only provide his/herself at large individual costs - e.g. privacy, internet connection, office equipment. The risk of emotional isolation and associated mental health concerns are lower if a person works in a space where other people are carrying similar tasks.

In addition, if a shared-office is located within a reasonable commuting time from home - where reasonable depends on commute mode alternatives and workers' preferences-, it may also increase physical activity in comparison to working from home. For instance, if a shared office is close enough to a worker's home, she/he may commute by walking, biking, or e-biking. These features are at the core of business opportunities identified in the midst of the COVID-19 pandemic in Mexico and elsewhere - e.g. as of November 2020, hotels and restaurants in Mexico have developed affordable near-home shared office environments aiming to attract office workers unsatisfied with teleworking from home (Forbes, 2020; Valadez, 2020).

Considering that $38 \%$ of workers in CDMX can potentially perform their job remotely (Monroy- 
Gómez-Franco, 2020), a question naturally arises: would office workers in CDMX be interested on teleworking from a shared office located near their home? Graizbord (2015) has identified producer services and wholesale trade as the two sectors with the most potential in CDMX to promote teleworking from home. Based on a survey answered by 72 teleworkers and their supervisors in CDMX in 2011, Graizbord (2015) has estimated that greenhouse gas emissions of teleworkers decrease in 9\% once a rebound effect is taken into consideration.

This paper estimates how much office workers in CDMX are willing to have their monthly paycheck cut in exchange for teleworking from a near-home shared office. In November and December 2019, a sample of 1,179 office workers in CDMX was presented to a discrete choice experiment (DCE) that describes an scenario under which the respondent can choose whether he/she would take the option offered by his/her employer of working two days a week from a shared office. If the respondent chooses teleworking from a shared office space, then the employer would cut her/his monthly paycheck in order to afford the shared office space. Respondents have chosen from among three alternatives - one of which is the status quo alternative. The two non-status quo alternatives have been described in terms of commuting time to the shared office, availability of safe parking spaces for bikes, and amount that would be taken from monthly paycheck. Each respondent has faced four choice sets.

Based on random parameter logit (RPL) specifications, we estimate that respondents' average willingness to pay (WTP) for teleworking two days a week from a shared office is (2019) MXP 1,460 (USD 76.68) on a monthly basis. 17 We also document that the average value of one-hour of commuting time is MXP 73.75 (USD 3.87). As economic theory suggests, heterogeneity in both welfare measures is associated with income and commuting time - wealthier respondents that spend less time in commuting report higher WTP for shared offices and higher values of commuting time. In addition, we report that the average monthly willingness to pay for spaces to park bikes is MXP 280 (USD 14.07) - this value remains similar to variations in income, commuting time and other variables.

From a big-picture point of view, this paper initiates a conversation about the possibility that a system of shared offices located within a reasonable distance from workers' homes may represent an alternative for megacities to not only tackle congestion in peak hours and associated air pollution but to increase resilience in a post-COVID-19 world. Practitioners and policy makers in megacities may find this conversation of interest as these cities encompass sectors and regions with large potential benefits from teleworking - particularly, those located in emerging economies (Ansong \& Boateng, 2018; Bojovic et al., 2020).

\section{Related literature}

This section places the contribution of this study within three literatures. One refers to the literature that has documented barriers to teleworking but has mostly focused on teleworking from home overlooking the potential benefits from teleworking in a shared office. The second literature of interest estimates value of commuting time on preferences stated under transportation scenarios. This paper's contribution to this literature is twofold. On one hand, it contributes by documenting the value of commuting time in a megacity located in an emerging economy - previous studies have mostly focused on cities located in developed countries. As a second contribution to the transportation literature, this paper belongs to a small number of discrete choice experiment studies inferring the value of commuting time from the trade-off between commuting time and wage - studies within this literature most frequently analyze between-mode choices or within-mode choices. The third literature to which this paper contributes is the one focused on commuting in CDMX - this literature have

\footnotetext{
${ }^{1}$ We use a exchange rate of $19.04 \mathrm{MXP} / \mathrm{USD}$, which was in place as of December 12th, 2019.
} 
overlooked office workers in CDMX, arguably, because the main source of information for commuting patterns in CDMX does not allow for a straightforward identification of office workers (see INEGI, 2018).

\subsection{Teleworking}

For nearly five decades, teleworking has been expected to become a popular working arrangement but it has not occurred so far. Before COVID-19 hit, only 9\% of USA's working population teleworked once a week (Zhu et al., 2018); in Europe, this number was around 5\% in 2017 (López-Igual \& Rodríguez-Modroño, 2020) —with national numbers reaching up to 30\% in Denmark, Netherlands, and Sweden (ILO, 2020) - ; 16\% in Japan, and only 1.6\% in Argentina (ILO, 2020).

In this respect, two literatures on teleworking are of interest. On of them has documented barriers to adoption of teleworking; the second one has documented how teleworking may not necessarily reduce energy use at an aggregated level.

Two recent reviews - carried out separately - have concluded that economy-wide energy savings from teleworking from home are likely modest and warn that, due to several uncertainties, there is a probability that energy savings could be negative (Hook et al., 2020; O'Brien \& Aliabadi, 2020). These reviews have accounted for behaviors of both teleworkers and members of their households in terms of reduced commuter travel, rebound effects, and impacts on energy consumption associated with changes in non-work travel and home energy consumption. While the main source of savings is the reduced distance travelled for commuting and lower office energy consumption, the potential for negative energy savings arise from the possibility that teleworking increases home energy use and non-work travel made by members of teleworkers' household. A caveat of the findings reported by Hook et al. (2020) and O'Brien \& Aliabadi (2020) is their reliance on evidence collected for contexts in developed economies.

From employees' point of view, barriers to adoption of teleworking include concerns about worklife balance, emotional isolation (particularly in the case of individuals living alone), and fearing that teleworking may imply missing out opportunities for career advancements (Golden et al., 2008, Schulte, 2015). These concerns are not unwarranted. For instance, the impact on work-life balance may go both ways because teleworking blurs boundaries between paid work and personal life domains (ILO, 2020). Also, employers tend to increase work load of teleworkers (Noonan \& Glass, 2012; Russell et al., 2009). In addition, teleworking from home has been documented to be strongly associated with the presence of children at home, with an spillover effect aggravating gender differences in the division of housework (Thulin et al., 2019; Zhang et al., 2020) — an effect that COVID-19 has brought to the forefront (see ILO, 2020).

From employers' point of view, teleworking represents challenges to accountability and measurement of productivity (Pérez et al., 2005). These challenges translate into an increase in managers' responsibilities and the corresponding time handling them. For instance, Microsoft in China has calculated that leading teleworking teams adds an extra 90 minutes per week to working time of managers - time that results from additional one-to-one calls and meetings (Sapataro, 2020). COVID-19 have made clear that an important barrier at the firm level is the lack of appropriate IT tools and devices, and lack of skill and training resources (ILO, 2020).

Additional barriers stem from concerns about data security and privacy issues (see ILO, 2020) - a particularly difficult obstacle in emerging economies with unclear regulatory frameworks, and weak laws protecting intellectual property rights and confidentiality of sensitive data (Mitter, 2000).

While most of previous research on teleworking has focused on teleworking from home, this paper puts forward the advantages that teleworking from a shared office may represent if this office space is located within a reasonable commuting time. For instance, people that live alone would likely 
face less risk of emotional isolation if they work from an office space where other people perform similar tasks. Also, work-life balance may be easier to reach if a person works in an out-of-home space that allows a clear division between personal and work domains. A healthy work-life balance would be more reachable if the office space is within reasonable commuting time as it would imply savings in commuting time that a worker can allocate to activities that improve his/her individual health, and/or social life. Depending on available infrastructure, less commuting time may incentivize workers to commute by walking, biking, or e-biking - with the corresponding effects on individual health and social welfare. Importantly in the context of megacities in emerging economies, the office conditions that a shared office space provides can hardly be provided by the employee him/herself if living in an overcrowded dwelling.

To the best of our knowledge, previous literature on teleworking has overlooked the possibility that teleworking from a near-home shared office may be an attractive option for office workers in emerging economies - and employers as well but we focus on employees here. Indeed, in the midst of the COVID-19 pandemic, restaurants and hotels have identified in Mexico a demand for affordable near-home shared office environments aiming to attract office workers unsatisfied with teleworking from home (Forbes, 2020; Valadez, 2020).

\subsection{Estimating the value of commuting time from the wage-commuting time trade-off}

The interest on the value of time is longstanding — with Becker (1965), Beesley (1965), and DeSerpa (1971) credited as pioneers of the microeconomic modelling of time allocation (Dubernet \& Axhausen, 2020). Current practice in the transportation literature heavily relies on stated preferences gathered through discrete choice experiments (DCE) (Beck et al., 2017; Dubernet et al., 2020). Supported by the random utility framework, researchers most frequently take advantage of single-journey, shortterm decisions to estimate the value of commuting time - either between-mode choices ${ }^{2}$ or withinmode choices $3^{3}$ (Beck et al., 2017; Swärdh \& Algers, 2016).

In the transportation literature, there are few DCE studies that have inferred the value of commuting time by analyzing the trade-off between commuting time and wage to estimate (Swärdh \& Algers, 2016) 4 This trade-off has presented itself as a natural candidate in this application because, as a by-product of our main objective, we explore how much wage office workers would give up under a range of commuting times - i.e. what is the commuting time that office workers would find reasonable if a shared office that is near their home is offered to them.

In this respect, our DCE is closest to the one designed by Swärdh \& Algers (2016). In 2005, they presented both earners in a sample of two-earner households residing in the Stockholm region, Sweden, to scenarios in which respondents receive offers trading-off longer commuting time and a higher wage - i.e. respondents chose to accept or to reject an offer where both wage and commuting time increase. Their main contribution arises from treating respondents with two different stated choice experiments. In the first one, respondents report their willingness to accept longer commuting time themselves - i.e. as if the offer was made to the respondent. In the second choice experiment, respondents report their willingness to accept or to reject offers where both the respondent and

\footnotetext{
${ }^{2}$ For instance, a trade-off between travel time and travel cost between a car and a bus.

${ }^{3}$ For instance, keeping mode constant, a trade-off between time and cost originated in the possibility of taking different routes, lanes, or destinations

${ }^{4}$ This trade-off has also been studied in the labor market — workers who are willing to commute a greater distance likely request a higher wage. Studies belonging to this literature are mostly based on revealed preferences data - e.g. Isacsson et al. (2013), French et al. (2020), Fu \& Viard (2019), Russo et al. (2012), and Van Ommeren \& Fosgerau (2009).
} 
his/her spouse simultaneously receive wage increases as compensation for longer commuting. With this split-sample approach, they aim to identify gender differences in respondent's value of his/her own commuting time compared to the respondents' value of his/her spouse's commuting time. They document that when respondent's own commuting time and attributes are the DCE's attributes, the estimated value of commuting time does not differ between men and women. In contrast, when valuing spouses' commuting time, both spouses value the commuting time of the wife highest.

Beck et al. (2017) and Dubernet et al. (2020) have pointed out that a decision between commuting distance/time and wage is a decision with lasting implications in terms of travel patterns of the decision makers because it changes choice sets for future short-term decisions over periods that typically cover several years or even decades. Thus, Beck et al. (2017) have borrowed the data gathered by Swärdh \& Algers (2016) to document significantly higher values of commuting time when scenarios involve long-term decisions in comparison to short-term ones. Pursuing a similar goal than Beck et al. (2017), Dubernet et al. (2020) analyze stated decisions to scenarios presented by the German Value of Time and Reliability Survey because this survey not only have presented salary gains — as in Swärdh \& Algers (2016) — but salary losses as well as salary neutral scenarios. They document opposite effects to those reported by Beck et al. (2017) when salary neutral situations are considered 5

In general, the literature on value of travel time has focused on developed economies - e.g. a recent literature review focused only on European cases has been able to cover 3,109 estimates reported in 389 studies (Wardman et al., 2016). This focus is not different when zooming on the few studies using DCE to infer value of commuting time from the wage-commuting time trade-off.

\subsection{Commuting in CDMX}

CDMX is the core of the Mexico City Metropolitan Area (MCMA), which is the largest metropolitan area in the Western Hemisphere and the fifth largest in the world. CDMX has been among the 10 most congested cities in the world from 2014 to 2018 - in 2019, CDMX left this inglorious group to be ranked $13^{\text {th }}$. In 2019, a car commuter wasted 195 hours (8 days and 3 hours) when driving in rush hours (TomTom, 2020).

Based on data gathered in 2007, Guerra (2017) documents that suburban households earn $30 \%$ less than urban households, have 40\% longer commutes, and spend nearly twice as much per transit trip. Martita's situation is illustrative: each morning, she leaves her house on the outskirts of CDMX at 6:30 a.m. to arrive at her cleaning job by $9 \mathrm{a} . \mathrm{m}$. This two-and-a-half hour one-way commute costs around a quarter of her daily wage (WRI, 2011). Guerra (2017) documents that 80\% of households use public transportation on a typical weekday and the poorest fifth of the households spend almost a quarter of their income on public transportation - twice as much as commonly used transportation affordability thresholds. Poor households are least able to reduce commuting expenditures without reducing travel because cars are expensive, non-discretionary trip distances are often too long for nonmotorized modes, and wealthier households price them out of the most accessible neighborhoods.

In 2017, 34.56 million of trips were carried out in a typical week in the MCMA; $58 \%$ of them involve commuting to work place. $37 \%$ of these trips involved no more than 30 minutes; $58 \%$, between 31 minutes and 2 hours; and 5\%, more than 2 hours. Trips from work place to home were shorter - $55 \%$ took less than 30 minutes; $41 \%$ took between 31 minutes and 2 hours; and 4\%, more than 2 hours (INEGI, 2018).

Avila-Forcada \& Medina-Martinez (2019) offer a look at changes occurred to commuting patterns

5 Rouwendal \& Meijer (2001) represents an earlier DCE application exploring the value of commuting time through the trade-off among wage, commuting time and housing attributes. 
in CDMX during the 2007-2017 period. This decade has witnessed an increase from 14 million to 19 million in the number of MCMA's residents, and an increase from 5.6 million to 12.27 million in the number of registered vehicles. The authors warn that, while in 2007 longer trips more likely involved public transportation, in 2017 these trips more likely involved private cars. Also, commuting by bike has more than doubled during the decade under analysis - an increase pushed by educated, older, and wealthier commuters in CDMX. They point out that, conditional on car ownership in the household, men and wealthier commuters more frequently commute by car.

Based on data collected in 2018 via online platforms, Hess \& Narteh-Yoe (2020) explore the interest of commuters in New Delhi, CDMX, Sao Paulo, Manilla, Nairobi, and Acra to reduce commuting time. They report that $18 \%$ of their respondents in CDMX spend 3 hours or more in commuting - a number that seems to be an overestimation in comparison to official estimates according to which $5 \%$ of commuters spend more than 2 hours (INEGI, 2018). Hess \& Narteh-Yoe (2020) estimate the average commuting time in 2018 in CDMX at 1.8 hours - with a median of 1.5 hours, and a mode of 30 minutes. A couple of their findings work as motivation for our study: $88 \%$ of respondents in CDMX reported to be aware of the negative impacts that long-time commuting has on their quality of life an health, and that $80 \%$ would be willing to make changes in their daily life so that commuting time is reduced.

We highlight that studies documenting commuting in CDMX have not explored preferences of office workers explicitly. This gap, we believe, is partially explained by the fact that the main source of information for commuting patterns in CDMX - the survey on households travel patterns - does not allow for an easy identification of office workers (see INEGI, 2018).

Only until recently, and directly motivated by the challenges imposed by COVID-19 in terms of teleworking from home, Monroy-Gómez-Franco (2020) has estimated that around 38\% of workers in CDMX can perform their duties remotely. Also, the author documents that salary of these workers fall in the upper tail of the hourly wage distribution - with only $5 \%$ generating a wage below the poverty line.

\section{Theoretical and empirical approaches}

\subsection{Random Utility Model}

The Random Utility Model (RUM) provides theoretical support to the empirical analysis of discrete choice experiments (see Train, 2009). The departure point of the RUM is that, when faced to $J$ mutually exclusive alternatives, individual $i$ chooses the alternative that provides him/her with the highest utility. An individual's indirect utility from each alternative is denoted as $U_{i j}$ for $i=1,2, \ldots, I$ and $j=1,2, \ldots, J$. The individual is assumed to know his/her own utility function with certainty. The researcher, however, cannot fully observe each $U_{i j}$. Thus, from the researcher's point of view and once a linear indirect utility function is assumed, $U_{i j}$ can be expressed as

$$
U_{i j}=V_{i j}+\epsilon_{i j}=\beta^{\prime} x_{i j}+\epsilon_{i j}
$$

where $V_{i j}$ is the component observed by the researcher; $x_{i j}$ is a $(M+1) X 1$ column vector denoting $M$ alternative-specific attributes and the alternative-specific intercept; $\beta$ is a $(M+1) X 1$ column vector representing the alternative-specific intercept, and the preferences for the alternative-specific attributes; and $\epsilon_{i j}$ represents the purely random heterogeneity that the researcher is unable to observe.

If an individual chooses the alternative associated to the highest utility, then the individual $i$ chooses $U_{i}^{\max }$, where

$$
U_{i}^{\max }=\max \left\{U_{i 1}, U_{i 2}, \ldots \ldots ., U_{i J}\right\}
$$


The willingness to pay (WTP) for the alternative associated to the highest utility is expressed as the monetary value of the utility derived from $U_{i}^{\max }$, i.e.,

$$
W T P_{i}=\frac{U_{i}^{\max }}{\beta_{p}}
$$

where $W T P_{i}$ is individual $i$ 's WTP; and $\beta_{p}$ is the price preference parameter. Under the assumption that indirect utility is linear in attributes, including income, $\beta_{p}$ is the negative of the marginal utility from income.

Under the assumptions embedded in equation (1), a researcher cannot observe $U_{i}^{\text {max }}$ as defined in equation (2). A researcher can only make statements in terms of expected utilities which are calculated over the error term $\epsilon_{i j}$, i.e.

$$
E\left(U_{i}^{\max }\right)=E_{\epsilon}\left[\max \left\{V_{i 1}, V_{i 2}, \ldots \ldots, V_{i J}\right\}\right]
$$

Under the assumption that $\epsilon_{i j}$ follow a type I extreme value distribution, the expected maximum utility can be calculated through the $\log$ sum formula ${ }^{6}$ i.e.

$$
E\left(U_{i}^{\max }\right)=\ln \sum_{j=1}^{J} \exp \left(V_{i j}\right)
$$

Accordingly, statements involving welfare measures are made in expected terms. For a before $(b)$ and an after $(a)$ situations - where after implies a change in the available alternatives - , the expected value of the compensation variation $(\mathrm{CV})$ due to the change in individual $i$ 's utility is expressed as

$$
\begin{aligned}
E_{\epsilon}\left(C V_{i}\right) & =\frac{1}{-\beta_{p}}\left(E_{\epsilon}\left(U_{i}^{\max , a}\right)-E_{\epsilon}\left(U_{i}^{\max , b}\right)\right) \\
& =\frac{1}{-\beta_{p}}\left(\ln \sum_{j=1}^{J} \exp \left(V_{i j}^{a}\right)-\ln \sum_{j=1}^{J} \exp \left(V_{i j}^{b}\right)\right)
\end{aligned}
$$

The marginal willingness to pay (MWTP) can be derived from equation (5) as follows. Assume attribute $q$ changes in a non-marginal fashion across all alternatives -i.e. $q^{a}=q^{b}+\Delta q$ is the level of $q$ after $\Delta q$ has been added to $q^{b}$. Introduce the change in $q$ in equation (5) and, because such a change occurs across all alternatives, factor it 7 . The expected CV can be expressed as follows

$$
E_{\epsilon}\left(C V_{i}[\Delta q]\right)=-\Delta q \frac{\beta_{q}}{\beta_{p}}
$$

where $\beta_{q}$ is the marginal utility from $q$.

Equation (6) reduces to the WTP for a marginal change across alternatives when $\Delta q=1$-i.e. when the change in $q$ is marginal, and

$$
E_{\epsilon}\left(M W T P_{i}\right)=-\frac{\beta_{q}}{\beta_{p}}
$$

Equation (7) can be interpreted as the ratio of the marginal utility from the attribute that changes and the negative of the marginal utility from income.

\footnotetext{
${ }^{6}$ Pioneer derivations of the log sum formula were independently developed by Ben-Akiva (1973) and McFadden (1973)

'Further details can be found in Haab \& McConnell (2002)
} 


\subsection{Econometric model}

Empirical estimations of the parameters required in the calculation of the expected MWTP (i.e. $\hat{\beta}_{q}$ and $\hat{\beta}_{p}$ ) can be obtained via a conditional logit econometric specification. The departure point of this empirical model is the same as to establish the theoretical expectations of the welfare measures under discrete choice modelling - i.e. $\epsilon_{i j}$ is distributed according to a type I extreme value distribution. Under this assumption, the probability that individual $i$ chooses alternative $j$ is expressed as follows

$$
\begin{aligned}
P_{i j} & =\operatorname{Pr}\left[V_{i j}+\epsilon_{i j}>V_{i k}+\epsilon_{i k} \forall k \neq j\right] \\
& =\operatorname{Pr}\left[\epsilon_{i j}>V_{i k}-V_{i j}+\epsilon_{i k} \forall k \neq j\right] \\
& =\frac{e^{V_{i j}}}{\sum_{k \in J} e^{V_{i k}}}=\frac{e^{\beta^{\prime} x_{i j}}}{\sum_{k \in J} e^{\beta^{\prime} x_{i k}}}
\end{aligned}
$$

A conditional logit (CL) specification faces two limitations to model empirical discrete choice data (Train, 2009). First, a CL can represent systematic variation (i.e. taste variation that is related to observed characteristics) but not random taste variation (i.e. differences in tastes that cannot be linked to observed characteristics). Second, the estimation of the CL probabilities implies proportional substitution across alternatives - more flexible, more realistic patterns cannot be fitted with a CL model. 8

The random parameters logit (RPL) results from adapting the CL model to incorporate nonsystematic heterogeneity in preferences and discard the proportional substitution across alternatives. The RPL turns out to be a highly flexible model that can approximate any random utility model (McFadden \& Train, 2000).

The RPL probabilities are the integrals of standard logit probabilities over a density of parameters. That is, keeping in mind equation (8), a RPL is a model whose choice probabilities can be expressed in the following form

$$
P_{i j}=\int \frac{e^{\beta^{\prime} x_{i j}}}{\sum_{k \in J} e^{\beta^{\prime} x_{i k}}} f(\beta) d \beta
$$

where $f(\beta)$ is a density function. The RPL probability is a weighted average of the logit probabilities evaluated at different values of $\beta$, with the weights given by the density function $f(\beta)$. In statistical terms, the weighted average of several functions is called a mixed function. Consequently, a RPL is a mixture of the logit function evaluated at different $\beta$ 's with $f(\beta)$ as the mixing function.

\section{Survey methods and data}

\subsection{Data collection}

Face-to-face surveys were carried out from November 23 to December 19, 2019. Potential respondents were randomly approached at 11 public plazas where office workers usually hang around with colleagues to take breaks and socialize during a typical working day. These 11 spots have been selected based on the density of office buildings where both private and public services are provided in CDMX. In calculating this density, we have included the following categories of services, as reported by the Mexican Database of Economic Units (INEGI, 2020): government services, communication services, corporate services, financial services, professional and scientific services. In deciding this selection criterion, we have considered both our focus on office workers and Graizbord (2015)'s insights about

\footnotetext{
${ }^{8} \mathrm{~A}$ third limitation is that a CL is not fitted to capture correlation over time (Train, 2009).
} 
the sectors with the most potential to take advantage of teleworking in CDMX. Figure 1 illustrates the match between our 11 sampling points and the density of office buildings in CDMX.

The survey protocol has included one filter question so that enumerators made sure respondents were office workers in CDMX - "Do you work in an office space located in CDMX?". The survey was composed by four sections. The first section gathered commuting information -i.e. mode(s), time, costs, and routine (e.g. whether the respondent commutes with colleagues or relatives). The second section gathered information about respondents' perceptions about his/her job (e.g. perception on whether he/she could perform his/her duties from a place different than employer's premises); jobrelated routines (e.g. number of job-related meetings attended weekly); and type of working space (e.g. own office versus shared office space). The third section presented respondents to a discrete choice experiment. The fourth section gathered respondent's and his/her household's socioeconomic information.

\subsection{Discrete choice experiment}

Our discrete choice experiment (DCE) describes an scenario under which a respondent can choose whether he/she would take the option offered by his/her employer of teleworking two days a week from a shared office. If the respondent chooses teleworking from a shared office space, then the employer would cut her/his monthly paycheck in order to afford the shared office space. The respondent has been told that, in case of choosing a shared office alternative, he/she can unenroll at any time.

Respondents have chosen from among three alternatives - one of which is the status quo alternative. The two non-status quo alternatives have been described in terms of commuting time to shared office space, availability of safe parking spots for bikes, and the amount that would be cut from monthly paycheck. As illustrated in table 1, commuting time was describe as walking time and it has taken four values - 15 minutes, 30 minutes, 45, minutes, and 60 minutes. Availability of parking spots for bikes is a binary attribute - taking value one when safe parking spots for bikes are available, and zero otherwise. The price attribute has taken four values - MXP 350, MXP 700, MXP 1,400, and MXP 2,500, on monthly basis.

Each respondent was faced to four choice sets, which belong to one of two blocks. This design has been created with no assumptions about priors with help of the Stata command dcreate, documented by Risa-Hole (2015) 9 $^{9}$ Figure 3 illustrates the choice sets presented in our DCE.

\subsection{Descriptive statistics}

Once observations with missing values have been dropped, our working sample contains 1,179 respondents. Table 2 reports descriptive statistics of our working sample. On average, the monetary commuting costs of our respondents is MXP 35 (USD 1.86) in a one-way commuting trip — with a maximum of MXP 500 (USD 26.26). In terms of self-reported income, around $52 \%$ of respondents earn MXP 15,000 (USD 787.81) on a monthly basis; 29\% earn between MXP 15,000 and MXP 30,000; and 18\%, more than MXP 30,000 (USD 1,575). On average, respondents to our survey spend 57 minutes in a one-way trip from home to their work place — with a maximum of 210 minutes (3 hours and 30 minutes). Considering both monetary and opportunity costs, our respondents spend MXP

\footnotetext{
${ }^{9}$ In contrast to commands in other software, dcreate does not report a measure of efficiency with respect to a full factorial design (e.g. SAS). Instead, it reports absolute D-efficiency measures which implies that a "design with a higher D-efficiency is more efficient than a design for the same experiment with a lower D-efficiency, but the number themselves don't mean much [...]" (Risa-Hole, 2016). In our case, our final design has a D-efficiency of 1.73 in comparison to 0.63 of our initial design.
} 
135 (USD 7.10) on average in a one-way commuting trip —with a maximum of MXP 806 (USD 42.33).

We offer insights on whether average numbers arising from our sample are reasonable ${ }^{10}$ For instance, average commuting time in our sample is 57 minutes. The official survey documenting commuting time and expenses in CDMX reports 56 minutes as average time for trips to work place (INEGI, 2018) — this official number includes all jobs, not only office-related ones. The maximum commuting time in our sample is 3 hours and 30 minutes. While this number may seem unreasonable at first, keep in mind that Official numbers report that $5 \%$ of commuters spend more than 2 hours (INEGI, 2018), and Hess \& Narteh-Yoe (2020) document that $18 \%$ of respondents to their survey in CDMX spend 3 hours or more in commuting 11 Thus, commuting times arising from our study fall within a feasible range of values.

In terms of commuting expenses, the average total cost of one-way trip in our sample is MXP 135. Assuming 20 working days a month, this value implies expenses of MXP 5,400 for 20 two-way trips. This number represents around 36\% of MXP 15,000 - monthly salary of a middle-income worker in Mexico (Milenio Digital, 2019). Previous studies have placed this percentage in around 40\% (Arredondo, 2017). Thus, commuting expenses documented by our study seem realistic.

In addition, we have compared origin-destination flows at the municipality level arising from our survey to those documented by the official survey on travel patterns (see INEGI, 2018). Around 84\% of the flows in our survey coincide with those of the official source, $13 \%$ flows have been oversampled by our survey, and $3 \%$ have been undersampled. Figure 2 illustrates the origin-destination flows captured by our study.

Table 2 reports that, in terms of commuting routines, $19 \%$ of respondents drop off a relative in their way to work; $23 \%$ of respondents coordinate with a colleague to commute to work; and $44 \%$ include running errands as part of their commuting routine.

In terms of job characteristics, table 2 shows that our respondents have been in their job 4.67 years on average; $39 \%$ of respondents work at a cubicle in room with no walls; $45 \%$ work at a cubicle in a room with walls; and $16 \%$ work in their own office. In terms their employer's sector, $78 \%$ of respondents work in a private company; $20 \%$ work in a public agency; and $2 \%$ work in a NGO or a research center or university. On average, respondents attend 3.82 meetings a week —with a maximum of 40 meetings a week; and $30 \%$ of respondents think that their duties can be performed from home. On average, respondents had attended 4 social gatherings with coworkers during last 3 months prior to the survey.

In terms of socioeconomic characteristics, table 2 reports that $40 \%$ of our respondents are women; 35 years old; and $37 \%$ are married. On average, respondents household is composed by 3.34 members. In terms of education, $22 \%$ of respondents hold a high school diploma or lower degree; $66 \%$ hold a bachelor's degree; and $11 \%$ hold a graduate degree.

\footnotetext{
${ }^{10}$ To the best of our knowledge, no previous study has explicitly documented commuting time and expenses of office workers in CDMX. Consequently, it is difficult to carry out comparisons of average numbers in our sample to numbers reported by previous studies.

${ }^{11}$ The difference between official numbers and those reported by Hess \& Narteh-Yoe (2020), we believe, originates in the data gathering strategy followed by Hess \& Narteh-Yoe (2020). Their data is gathered via online platforms. This strategy, we argue, has likely oversampled workers with more qualifications - as digital literacy is actually necessary to answer online surveys. In this respect, numbers reported by Hess \& Narteh-Yoe (2020) may reflect patterns of a population similar to ours.
} 


\section{Results}

Table 3 reports results from three logit specifications. The first set of parameters result from a conditional logit specification; the second one, from a random parameters logit that assumes all parameters, including the price parameter, are normally distributed and uncorrelated; and the third specification drops the no correlation assumption.

The signs of all four parameters are as expected across the three econometric specifications. The alternative-specific parameter reflecting preference for not remaining in status quo is positive indicating a preference for alternatives that imply teleworking from a shared office. The commuting time parameter is negative - indicating disutility from time spent in commuting. The parameter capturing preferences for spaces to safely park bikes is positive -indicating a preference for presence of infrastructure facilitating commuting by bike. The parameter associated with price is negative - indicating a disutility from seeing salaries cut on monthly basis. All parameters are significant at $99 \%$ of confidence.

Unobserved heterogeneity is confirmed by the estimates arising from both random parameters specifications. The specification with uncorrelated parameters yields statistically significant standard deviations for all four parameters - all of them at $99 \%$ of confidence. The specification with correlated parameters yields statistically significant standard deviations for three parameters - the exception being the standard deviation of the commuting time parameter. In addition, four correlations parameters are statistically significant but those involving commuting time reflect counterintuitive patterns. In particular, the positive correlation between commuting time and the alternative-specific parameter reflecting preference for teleworking is counterintuitive - we would expect that higher preferences for teleworking are associated with lower preferences for commuting time. Following a similar reasoning, the positive correlation between commuting time and parking spaces is unexpected as well.

The bottom panel of table 3 reports Akaike Information Criterion (AIC) and Bayesian Information Criterion (BIC) for each specification. According to both criteria, random parameters specifications outperform the conditional logit model. According to AIC, both random parameters specifications perform similarly - 7,334 for both. According to BIC, the specification assuming no correlation outperforms the one assuming correlation among parameters - 7,395 versus 7,440.

Table 4 reports marginal willingness to pay (WTP) arising from the three specifications reported in table 3. The first set of estimates refer to WTP for not remaining in status quo -i.e. WTP for alternatives that involve teleworking. The second set of estimates refer to WTP for one hour of commuting -i.e. the value respondents' assign to one hour of commuting. The negative sign of this WTP reflects that respondents require compensation for bearing one hour of commuting. The third set of estimates refer to the WTP for availability of spaces to park bikes. Numbers in table 4 are expressed in monthly thousand MXP.

We highlight that, as table 4 shows, while point estimates of WTP differ across the three specifications, their 95\% confidence intervals largely intersect. For instance, WTP for teleworking alternatives is estimated at MXP 1,300 on monthly basis through the conditional model; at MXP 1,460 on monthly basis via the random parameters model with no correlation; and at MXP 1,490 on monthly basis via the random parameters model with correlation. The upper bound of the conditional logit estimate (MXP 1,420) fall well within the 95\% confidence intervals of the other two models - MXP 1,330 to 1,580, and MXP 1,360 to 1,630, respectively. A similar reasoning arises when paying attention to the other two sets of WTP estimates.

Through the rest of this paper, we focus our attention on estimates arising from the random parameters specification that assumes no correlation among parameters. In choosing these estimates as our preferred ones, we have considered the criteria. First, AIC and BIC together suggest that adding the assumption of correlation does not improve the statistical performance of the econometric 
specification. Second, the model assuming correlation among parameters yields correlation parameters with counterintuitive signs for the commuting time parameter at the same time that yield an insignificant standard deviation for the commuting time parameter. Third, point estimates of WTP arising from both random parameters specifications are similar and their $95 \%$ confidence intervals largely intersect.

Thus, our preferred estimation of the average WTP for a teleworking alternative is MXP 1,460 (USD 76.68) on a montly basis — as reported in the second column of table 4. The average monthly value of one hour of commuting time is estimated at MXP 1,180 (USD 61.97); and the average WTP for bike parking spaces is MXP 280 (USD 14.07) on monthly basis.

The monthly WTP for one hour of commuting time must be interpreted as the value assigned by the respondent to 16 hours of commuting time over a given month. This interpretation results from the phrasing of the scenario under valuation. As the respondent ponders teleworking two days a week in exchange for a discount to his/her monthly check, if teleworking is chosen then the respondent saves him/herself eight two-way trips during a given month. Thus the hourly value is obtained by dividing MXP 1,180 over 16, which yields MXP 73.75 (USD 3.87).

In addition to estimates of average estimates of WTP arising when controlling for unobserved heterogeneity, we have explored for the presence of observed heterogeneity. Factors under consideration that have turned out statistically insignificant in our explorations include i) gender, ii) age, iii) marital status, iv)whether respondent works for public or private employers, v) whether respondent coordinates with relatives or colleagues as part of his/her commuting routine, vi) respondent's type of office space at employer's premises, vii) number of meetings respondent attends on a given month, and viii) total commuting costs.

Two factors that have turned out relevant to explain observed heterogeneity are respondent's income, and respondent's commuting time. Based on self-reported monthly income, we have classified respondents into two categories. The first category encompasses 620 respondents with income below MXP 15,000 (USD 787.82); and the second category is composed by 559 respondents with income above MXP 15,000 - this amount is used as a threshold to define who belongs to the middle-income class in Mexico (Milenio Digital, 2019). Based on commuting time, we have classified respondents into two categories as well —one is composed by 606 respondents with commuting time below 50 minutes; and the other is composed by 573 with commuting time above 50 minutes - this number is the median of commuting time in our sample.

Table 5 reports average estimates of WTP for respondents in each category of self-reported income, commuting time, and total commuting costs - we report estimates based on the median of commuting costs to illustrate factors that that have not yielded evidence of observed heterogeneity. These estimates arise from random parameters specifications with no correlation —as reported in tables A1, A2, and A3.

As economic theory suggests, and as illustrated by table 5. WTP estimates vary by income and by commuting time. For the case of WTP for teleworking alternatives, while those with income above MXP 15,000 (USD 787.82) would pay MXP 1,650 (USD 86.65), those with less than MXP 15,000 would pay MXP 1,260 (USD 66.17) - the 95\% confidence intervals of these point estimates do not intersect. Similarly, wealthier respondents report a monthly value for one hour of commuting of MXP 1,520 (USD 79.83) versus MXP 880 (USD 46.21) which is the value assigned by less wealthy respondents. Also, a statistically different value of time can be documented when focusing on categories based on commuting time. Those spending less than 50 minutes in commuting assign a monthly value of MXP 1,550 (USD 81.41) to one hour of commuting, and those spending more than 50 minutes assign a value of MXP 830 (43.59). WTP for spaces to park bikes does not significantly vary across income or commuting time categories.

In addition, we have explored whether observed heterogeneity can be modelled by interacting the 
categories of income and commuting time. Figures 4, 5, and 6 illustrate the results from these interactions. In particular, restricting attention to respondents with commuting time below 50 minutes, those with income above MXP 15,000 (USD 787.82) report MXP 1,830 (USD 96.11) as willingness to pay for teleworking from a shared office two days a week, and respondents with income below MXP 15,000 report MXP 1,190 (USD 62.50). With respect to monthly value of commuting time, respondents with income below MXP 15,000 and commuting time above 50 minutes report lower value of commuting time than respondents with income above MXP 15,000 and commuting time below 50 minutes - MXP 790 (USD 41.49) versus MXP 2,200 (115.54). The average monthly willingness to pay for spaces to park bikes is MXP 280 (USD 14.07) — this value remains similar to variations in income, commuting time and other variables.

\section{This paper's estimates in context}

The most novel contribution of this study is the estimation of WTP of office workers in CDMX for teleworking from a near-home shared office two days a week. This WTP is estimated at around (2019) MXP 1,460 (USD 76.68) on a monthly basis. This number represents $8.40 \%$ of average monthly income of respondents in our sample. It also represents $33.76 \%$ of average total commuting costs of 16 two-way trips to their current office - i.e. number of two-way trips involved in the teleworking scenario under analysis. Indeed, this WTP varies depending on income and commuting time of a respondent. The highest WTP is MXP 1,830 (USD 96.11) and it is reported by wealthier office workers with a commuting time lower than 50 minutes. The lowest WTP is MXP 1,190 (USD 62.50) and it is reported for less wealthy office workers with a commuting time lower than 50 minutes.

These WTP estimates suggest that teleworking from a near-home shared office is in demand among office workers in CDMX, and that office workers' WTP is at or close to market prices. In 2019, WeWork charged around MXP 4,500 per month (USD 236.34) per desk space in CDMX ${ }^{12}$ This rate is equivalent to MXP 225 (USD 11.82) per working day. Our average WTP translates into a daily rate of MXP 182.5 (USD 9.58); and our highest WTP translates into MXP 228 (USD 11.97) -just at Wework's rate.

A second set of estimates reported in this paper refers to the value of one hour of commuting time. The average value is estimated at MXP 73.75 (USD 3.87). The highest value is MXP 137.50 (USD 7.22) - reported by wealthier respondents spending less than the median commuting time-; and the lowest value is 49.38 (USD 2.59) - reported by less wealthy workers with higher than the median commuting time. The average value of commuting time seems reasonable when we compared to the average total commuting cost of a one-round trip in our sample - MXP 135.14 (USD 7.10).

When comparing our estimates of value of one hour of commuting time to previous results, we wish to highlight that, to the best of our knowledge, no previous study has estimated this parameter for office workers in CDMX. A recent review of values of travel time in Europe, covering 3,109 monetary valuations from 389 studies, reports estimates of commuting time covering a range of values from (2019) USD 9.93 to USD 14.75 (Wardman et al., 2016) 13 While our average and lowest estimates fall below these numbers, we highlight that our highest estimate is close to Europe's lowest value (USD 7.22 versus USD 9.93).

Together, WTP for teleworking from a shared office and monthly value of one hour of commuting time provide estimates of WTP for teleworking from shared offices under different commuting time scenarios. For instance, taking average values, a respondent's WTP for teleworking two days a week

\footnotetext{
${ }^{12}$ Personal communication with administrative personnel of an NGO leasing shared space from WeWork.

${ }^{13}$ Numbers are reported in Euros in original study. We have used an exchange rate of 1 USD/1.11 Euros, which was in place in December 12th, 2019.
} 
from a shared office located a few steps from his/her home is MXP 1,460. If he/she has to commute one hour to a shared office then his/her WTP is calculated by subtracting MXP 1,180 to MXP 1,460. That is, MXP 280 (USD 14.07) is a respondent's WTP for teleworking two days a week from an office that is one hour away from his/her home. Considering that average commuting time is 57 minutes, it seems reasonable that our respondents' average WTP for teleworking is almost out-weighted by a one hour of commuting. That is, working from a shared office becomes unappealing if the commuting time is similar to the time that office workers are currently spending in commuting.

A final estimate reported in this study refers to average WTP for spaces to park bikes - MXP 280 (USD 14.07) on monthly basis. This number reflects benefits that office workers would experience with infrastructure to safely park their bikes if they commuted by bike. To put context to this estimate, we point out that it is twice as much to the highest value of one hour of commuting time estimated in this study. That is, our respondents' monthly benefits from infrastructure to park safely their bikes double the value of one hour of commuting time of the wealthier workers.

\section{Conclusions and discussion}

The COVID-19 pandemic has made clear that teleworking is an essential feature of resilient societies. Once the COVID-19 pandemic is over, whether or not teleworking finally takes off will depend upon effectiveness of solutions to challenges of teleworking from home. This paper has first highlighted that several of these challenges can potentially be overcome if teleworking is performed from a shared office space that is located within a reasonable commuting time from an office worker's home. Then, this paper has pondered whether this alternative is attractive to office workers in CDMX. Findings suggest that office workers' WTP for a shared office space in 2019 was around 2019 price markets.

If widely adopted in CDMX, teleworking from a near-home shared office may reduce work-related trips and, in turn, alleviate congestion during peak hours. It may also reduce net energy consumption and corresponding carbon emissions when considering work and non-work travel, and home and office energy use. While recent literature suggests that these net energy savings may in reality be modest or non-existent (Hook et al., 2020; O'Brien \& Aliabadi, 2020), these conclusions are based on literature that focuses on teleworking from home in cities of developed economies. A bigger picture is needed and it should include differences in energy efficiency in office spaces and dwellings in cities of emerging economies. This bigger picture would also consider benefits from teleworking that span to other domains such as value of saved commuting time and the potential for an increase in social capital. In this respect, promotion of teleworking from a near-home shared office can also be linked to arguments that, in 1960s, were used to label it as a social policy to enable workers to spend more time with their families (Hook et al., 2020). In addition, benefits from teleworking include its contribution to resilience. Together with providing values of willingness to pay for teleworking from a shared office, this study has also documented stated benefits for biking infrastructure in CDMX — which is also expected to increase if CDMX increases its resilience.

In this respect, the findings from this study belong to a broader conversation about how to pursue more ambitious goals by taking advantage of the change in routines that COVID-19 has imposed worldwide - e.g. CDMX's residents quickly embraced teleworking to face COVID-19's lockdown; and more recently, as the city tries to return from the lockdown, biking to work is becoming a popular commuting alternative. Policies pursuing improvement in resilience of a city will increase and enhance biking networks, ${ }^{14}$ discourage the use of private cars, and encourage the use of public

\footnotetext{
${ }^{14}$ The administration of CDMX has improvised bike lanes in main avenues as the city is facing the pandemic but unsafe conditions remain and 19 bikers have been injured when commuting (Stettin, 2020). This situation illustrates the need of safe biking networks on CDMX.
} 
transportation (Bojovic et al., 2020).

The idea of developing self-sufficient neighborhoods or 15-minute cities has recently gained track among policy makers and politicians (e.g. C40CCLG, 2020; Willsher, 2020). These neighborhoods would have offices, sports facilities, schools, medical centers, and shops within reasonable distance. Teleworking from a near-home shared office fits into the pursuing of a self-sufficient neighborhood. Further exploration of factors explaining heterogeneity in preferences is warranted, and would fit into the conversation on how to pursue self-sufficient neighborhood in the near future in cities of emerging economies. In particular, this paper does not explore spatially- and regionally-driven differences in WTP for shared offices - e.g. keeping commuting time and/or distance fixed, there may be differences in WTP explained by whether office workers commute from the north o the south of CDMX. This exploration would inform the designA of optimal networks of shared offices across CDMX - these networks would optimize societal net costs reflecting workers' direct benefits and positive externalities to the entire society. Indeed, research on this topic is ongoing.

\section{Acknowledgements}

This study was financed by the The Research Institute for Equitable Development (EQUIDE) of Universidad Iberoamericana Ciudad de México-Tijuana. We are thankful for the assistance provided by Ricardo Betancourt, Juan Regino Maldonado, and Ana Penella. All remaining errors are responsibility of the authors alone. 


\section{References}

Aguilera, A., Lethiais, V., Rallet, A., \& Proulhac, L. (2016). Home-based telework in france: Characteristics, barriers and perspectives. Transportation Research Part A: Policy and Practice, 92, $1-11$.

Ansong, E., \& Boateng, R. (2018). Organisational adoption of telecommuting: Evidence from a developing country. The Electronic Journal of Information Systems in Developing Countries, 84, e12008.

Arellano García, C. (2020). Recaen en las mujeres el aumento de home office. URL: https://www.jornada.com.mx/ultimas/sociedad/2020/07/29/ recaen-en-las-mujeres-el-aumento-del-2018home-office2019-849.html Accessed November $8,2020$.

Arredondo, I. (2017). Traficalinos. URL: https://www. eluniversal.com.mx/articulo/periodismo-de-investigacion/2017/01/10/ traficalinos-chilangos-pasan-hasta-45-dias-al-ano-en Accessed November 8, 2020.

Avila-Forcada, S., \& Medina-Martinez, I. (2019). Commuting trends in Mexico City (20072017). URL: https://www.researchgate.net/publication/333353856_Commuting_trends_ in_Mexico_City_2007-2017_a Accessed January 4, 2021.

Beck, M. J., Hess, S., Cabral, M. O., \& Dubernet, I. (2017). Valuing travel time savings: A case of short-term or long term choices? Transportation research part E: logistics and transportation review, 100, 133-143.

Becker, G. S. (1965). A theory of the allocation of time. The economic journal, 75, 493-517.

Beesley, M. E. (1965). The value of time spent in travelling: some new evidence. Economica, 32, 174-185.

Ben-Akiva, M. E. (1973). Structure of passenger travel demand models. Ph.D. thesis Massachusetts Institute of Technology. URL: http://onlinepubs.trb.org/Onlinepubs/trr/1974/ 526/526-003.pdf.

Bojovic, D., Benavides, J., \& Soret, A. (2020). What we can learn from birdsong: Mainstreaming teleworking in a post-pandemic world. Earth System Governance, 5, 100074.

C40CCLG - C40 Cities Climate Leadership Group- (2020). How to build back better with a 15-minute city. URL: https://www.c40knowledgehub.org/s/article/ How-to-build-back-better-with-a-15-minute-city?language=en_US Accessed November 11, 2020 .

Chang, C. J. (2019). The Effects of Work-Life Policies: Teleworking and Paid Family Leave. Ph.D. thesis University of Illinois at Chicago.

DeSerpa, A. C. (1971). A theory of the economics of time. The Economic Journal, 81, 828-846.

Dubernet, I., \& Axhausen, K. W. (2020). The german value of time and value of reliability study: the survey work. Transportation, 47, 1477-1513. 
Dubernet, I., Dubernet, T., \& Axhausen, K. W. (2020). Comparing values of travel time obtained from workplace and short-term decisions. Travel Behaviour and Society, 20, 83-90.

Forbes (2020). Vips quiere que clientes hagan home office en sus restaurantes. URL: https://www . forbes.com.mx/negocios-vips-office-el-nuevo-concepto-de-oficina-remota-de-vips/ Accessed November 8, 2020.

French, M. T., Popovici, I., \& Timming, A. R. (2020). Analysing the effect of commuting time on earnings among young adults. Applied Economics, (pp. 1-16).

Fu, S., \& Viard, V. B. (2019). Commute costs and labor supply: evidence from a satellite campus. Journal of Economic Geography, 19, 723-752.

Golden, T. D., Veiga, J. F., \& Dino, R. N. (2008). The impact of professional isolation on teleworker job performance and turnover intentions: Does time spent teleworking, interacting face-to-face, or having access to communication-enhancing technology matter? Journal of Applied Psychology, 93, 1412 .

Graizbord, B. (2015). Teleworking as a mobility strategy for mexico city. International Planning Studies, 20, 112-130.

Guerra, E. (2017). Does where you live affect how much you spend on transit? the link between urban form and household transit expenditures in mexico city. Journal of Transport and Land Use, 10, 855-878.

Haab, T. C., \& McConnell, K. E. (2002). Valuing environmental and natural resources: the econometrics of non-market valuation. Edward Elgar Publishing.

Hess, A., \& Narteh-Yoe, S. B. (2020). Productivity, sustainability, and economic growth in metropolises: Estimates of long-time commuting effects in developing countries, . URL: https: //www.researchgate.net/profile/Aurelio_Hess/publication/341608955_Productivity_ Sustainability_and_Economic_Growth_in_Metropolises_Estimates_of_Long-Time_ Commuting_Effects_in_Developing_Countries/links/5eca742e458515626cc72822/ Productivity-Sustainability-and-Economic-Growth-in-Metropolises-Estimates-of-Long-Time-C pdf. Accessed January 4, 2020.

Hook, A., Sovacool, B. K., Sorrell, S. et al. (2020). A systematic review of the energy and climate impacts of teleworking. Environmental Research Letters, 15, 093003.

ILO - International Labour Organization - (2020). Teleworking during the COVID-19 pandemic and beyond -A practical guide. URL: https://www.ilo.org/wcmsp5/groups/public/---ed_ protect/---protrav/---travail/documents/publication/wcms_751232.pdf Accessed November 8, 2020.

INEGI - Instituto Nacional de Estadistica y Geografia- (2018). Comunicado de presa 104/18 sobre la Encuesta de Origen-Destino en Hogares de la Zona Metropolitana del Valle de México (EOD) 2017. URL: https://www.inegi.org.mx/contenidos/saladeprensa/boletines/2018/ EstSociodemo/OrgenDest2018_02.pdf Accessed January 4, 2021.

INEGI - Instituto Nacional de Estadistica y Geografia-, t. . D. n. . A. u. . h., year = 2020 (). 
Isacsson, G., Karlström, A., \& Swärdh, J.-E. (2013). The value of commuting time in an empirical on-the-job search model-an application based on moments from two samples. Applied Economics, $45,2827-2837$.

López-Igual, P., \& Rodríguez-Modroño, P. (2020). Who is teleworking and where from? exploring the main determinants of telework in europe. Sustainability, 12, 8797.

McFadden, D. (1973). Conditional logit analysis of qualitative choice behavior. Frontiers in Econometrics, (pp. 105-142). URL: https://eml.berkeley.edu/reprints/mcfadden/zarembka.pdf.

McFadden, D., \& Train, K. (2000). Mixed mnl models for discrete response. Journal of applied Econometrics, 15, 447-470.

Mendoza Rojas, M. (2020). Home office suma 39 horas semanales de trabajo doméstico a mujeres. URL: https://www.publimetro.com.mx/mx/noticias/2020/08/02/ mujeres-home-office-suma-39-horas-semanales-trabajo-domestico-mexicanas.html Accessed November 2, 2020.

Milenio Digital (2019). ¿Cuánto debes ganar para ser de clase media. URL: https://www.milenio. com/negocios/cuanto-debes-ganar-en-mexico-para-ser-de-la-clase-media Accessed January $6,2021$.

Mitter, S. (2000). Teleworking and teletrade in india: combining diverse perspectives and visions. Economic and Political Weekly, (pp. 2241-2252).

Monroy-Gómez-Franco, L. (2020). ¿Quién puede trabajar desde casa? Evidencia desde México. URL: https://ceey.org.mx/quien-puede-trabajar-desde-casa-evidencia-desde-mexico/ Accessed January 4, 2021.

Noonan, M. C., \& Glass, J. L. (2012). The hard truth about telecommuting. Monthly Lab. Rev., 135,38 .

O'Brien, W., \& Aliabadi, F. Y. (2020). Does telecommuting save energy? a critical review of quantitative studies and their research methods. Energy and Buildings, (p. 110298).

Pérez, M. P., Sánchez, A. M., de Luis Carnicer, P., \& Jiménez, M. J. V. (2005). The differences of firm resources and the adoption of teleworking. Technovation, 25, 1476-1483.

Risa-Hole, A. (2015). DECREATE: Stata module to create efficient designs for discrete choice experiments. URL: https://ideas.repec.org/c/boc/bocode/s458059.html Accessed January 4, 2021.

Risa-Hole, A. (2016). Answer to Can I ask you to interpret the D-efficiency calculated by dcreate? URL: https://www.statalist.org/forums/forum/general-stata-discussion/general/ 1308477-dcreate-a-new-module-for-creating-efficient-designs-for-discrete-choice-experimer Accessed January 5, 2021.

Rouwendal, J., \& Meijer, E. (2001). Preferences for housing, jobs, and commuting: a mixed logit analysis. Journal of regional science, 41, 475-505.

Russell, H., O’Connell, P. J., \& McGinnity, F. (2009). The impact of flexible working arrangements on work-life conflict and work pressure in ireland. Gender, Work $\&$ Organization, 16, 73-97. 
Russo, G., van Ommeren, J., \& Rietveld, P. (2012). The university workers' willingness to pay for commuting. Transportation, 39, 1121-1132.

Sapataro, J. (2020). Key findings about remote work: lessons from our colleagues in china. URL: https://www.microsoft.com/en-us/microsoft-365/blog/2020/04/17/ key-findings-remote-work-lessons-colleagues-china/ Accessed November 15, 2020.

Schulte, M. (2015). Distance faculty experiences: A personal perspective of benefits and detriments of telecommuting. The Journal of Continuing Higher Education, 63, 63-66.

Stettin, C. (2020). Pese a ciclovia, van 19 ciclistas atropellados en Insurgentes. URL: https://ww.milenio.com/politica/comunidad/ pese-ciclovia-19-ciclistas-atropellados-avenida-insurgentes Accessed November $17,2020$.

Swärdh, J.-E., \& Algers, S. (2016). Willingness to accept commuting time within the household: stated preference evidence. Transportation, 43, 219-241.

Thulin, E., Vilhelmson, B., \& Johansson, M. (2019). New telework, time pressure, and time use control in everyday life. Sustainability, 11, 3067.

TomTom Traffic Index (2020). Mexico city traffic. URL: https://www.tomtom.com/en_gb/ traffic-index/mexico-city-traffic/ Accessed January 5, 2021.

Train, K. E. (2009). Discrete choice methods with simulation. Cambridge university press.

USOPM -U.S. Office of Personnel Management- (2020). What is telework? URL: https://www. opm.gov/faqs/topic/pandemic/index.aspx Accessed November 2, 2020.

Valadez, R. (2020). Workation: hoteles se lanzan a la caza de clientes que hagan home office. URL: https://www.milenio.com/negocios/ workation-hoteles-lanzan-caza-clientes-home-office Accessed November 8, 2020.

Van Ommeren, J., \& Fosgerau, M. (2009). Workers' marginal costs of commuting. Journal of Urban Economics, 65, 38-47.

Vázquez, G. (2020). Conexión a internet, soporte del home office y homeschooling. URL: https:// WWW.milenio.com/aula/conexion-internet-soporte-home-office-homeschooling Accessed November 2, 2020.

Wardman, M., Chintakayala, V. P. K., \& de Jong, G. (2016). Values of travel time in europe: Review and meta-analysis. Transportation Research Part A: Policy and Practice, 94, 93-111.

Willsher, K. (2020). Paris mayor unveils 15-minute city plan re-election campaign. URL: https://www.theguardian.com/world/2020/feb/07/ paris-mayor-unveils-15-minute-city-plan-in-re-election-campaign Accessed November $17,2020$.

WRI Ross Center for Sustainable Cities (2011). Snapshot/Martita. URL: https://www youtube . com/watch?v=NTQuhuyu60A\&feature=youtube_gdata_player Accessed January 4, 2021.

Zhang, S., Moeckel, R., Moreno, A. T., Shuai, B., \& Gao, J. (2020). A work-life conflict perspective on telework. Transportation Research Part A: Policy and Practice, 141, 51-68. 
Zhu, P., Wang, L., Jiang, Y., \& Zhou, J. (2018). Metropolitan size and the impacts of telecommuting on personal travel. Transportation, 45, 385-414. 


\section{Tables}

Table 1: Attributes and levels in discrete choice experiment.

\begin{tabular}{|c|c|c|}
\hline Attribute & Description (units) & Levels $^{a}$ \\
\hline \multirow{4}{*}{ Commuting time } & \multirow{4}{*}{ Time in one-way trip by walking (minutes) } & 15 \\
\hline & & 30 \\
\hline & & 45 \\
\hline & & 60 \\
\hline \multirow{2}{*}{ Bike parking } & \multirow{2}{*}{ Spots to park bikes (binary; 0/1) } & No parking spots \\
\hline & & Parking spots \\
\hline \multirow{4}{*}{ Price } & \multirow{4}{*}{ Amount subtracted from monthly paycheck (MXP) } & 350 \\
\hline & & 700 \\
\hline & & 1,400 \\
\hline & & 2,500 \\
\hline
\end{tabular}

Table 2: Descriptive statistics of entire sample (1,179 respondents)

\begin{tabular}{|c|c|c|c|c|}
\hline Variable & Mean & Std. Dev. & Min & Max \\
\hline \multicolumn{5}{|l|}{ Commuting expenses and income } \\
\hline MC: Monetary cost of commuting (MXP) & 35.55 & 46.29 & 0.00 & 500.00 \\
\hline 1 if self-reported monthly income $<=10 \mathrm{~K}$ MXP & 0.26 & 0.44 & 0.00 & 1.00 \\
\hline 1 if self-reported monthly income between $10 \mathrm{~K}$ and $15 \mathrm{~K}$ MXP & 0.26 & 0.44 & 0.00 & 1.00 \\
\hline 1 if self-reported monthly income between $15 \mathrm{~K}$ and $30 \mathrm{~K}$ MXP & 0.29 & 0.46 & 0.00 & 1.00 \\
\hline 1 if self-reported monthly income $>30 \mathrm{~K}$ MXP & 0.18 & 0.38 & 0.00 & 1.00 \\
\hline OP: Opportunity cost of commuting (MXP/minutes) & 1.82 & 1.09 & 0.52 & 3.64 \\
\hline $\mathrm{T}$ : Commuting time (minutes) & 57.24 & 33.36 & 5.00 & 210.00 \\
\hline TC: Total cost of commuting, $\mathrm{MC}+\mathrm{OP}^{*} \mathrm{~T}(\mathrm{MXP})$ & 135.14 & 110.10 & 2.61 & 806.10 \\
\hline \multicolumn{5}{|l|}{ Commuting routines } \\
\hline 1 if commuting routine includes dropping off a relative & 0.19 & 0.39 & 0.00 & 1 \\
\hline 1 if commuting routine includes coordinating with colleague & 0.23 & 0.42 & 0.00 & 1 \\
\hline 1 if commuting routine includes running errands & 0.44 & 0.50 & 0.00 & 1 \\
\hline \multicolumn{5}{|l|}{ Office space, and job routines } \\
\hline Years in current job & 4.67 & 6.37 & 0.08 & 39 \\
\hline 1 if cubicle in room with no walls & 0.39 & 0.49 & 0.00 & 1 \\
\hline 1 if cubicle in room with walls & 0.45 & 0.50 & 0.00 & 1 \\
\hline 1 if own office & 0.16 & 0.37 & 0.00 & 1 \\
\hline 1 if private sector & 0.78 & 0.42 & 0.00 & 1 \\
\hline 1 if public sector & 0.20 & 0.40 & 0.00 & 1 \\
\hline 1 if NGO or research center & 0.02 & 0.15 & 0.00 & 1 \\
\hline Number of average weekly job-related meetings & 3.82 & 5.23 & 0.00 & 40 \\
\hline 1 if respondent thinks his/her duties can be performed from home & 0.30 & 0.46 & 0.00 & 1 \\
\hline Social gatherings with coworkers during last 3 months & 3.91 & 6.22 & 0.00 & 60 \\
\hline \multicolumn{5}{|l|}{ Respondent's socioeconomic characteristics } \\
\hline 1 if respondent is female & 0.40 & 0.49 & 0.00 & 1 \\
\hline Respondent's age & 35.02 & 10.27 & 18.00 & 73 \\
\hline 1 if respondent is married & 0.37 & 0.48 & 0.00 & 1 \\
\hline Number of members of respondent's household & 3.34 & 1.62 & 1.00 & 15 \\
\hline 1 if high school diploma or less & 0.22 & 0.42 & 0.00 & 1 \\
\hline 1 if bachelor's degree & 0.66 & 0.47 & 0.00 & 1 \\
\hline 1 if graduate degree & 0.11 & 0.32 & 0.00 & 1 \\
\hline
\end{tabular}

${ }^{1}$ Based on self-reported range of monthly income. Mean values of each range has been divided by 20 working days, by 8 working hours, and by 60 minutes. For the more than $30 \mathrm{~K}$ range, we have assumed an average of 35,000 MXP. 
Table 3: Conditional and random parameter logit specifications on entire sample (1,179 respondents)

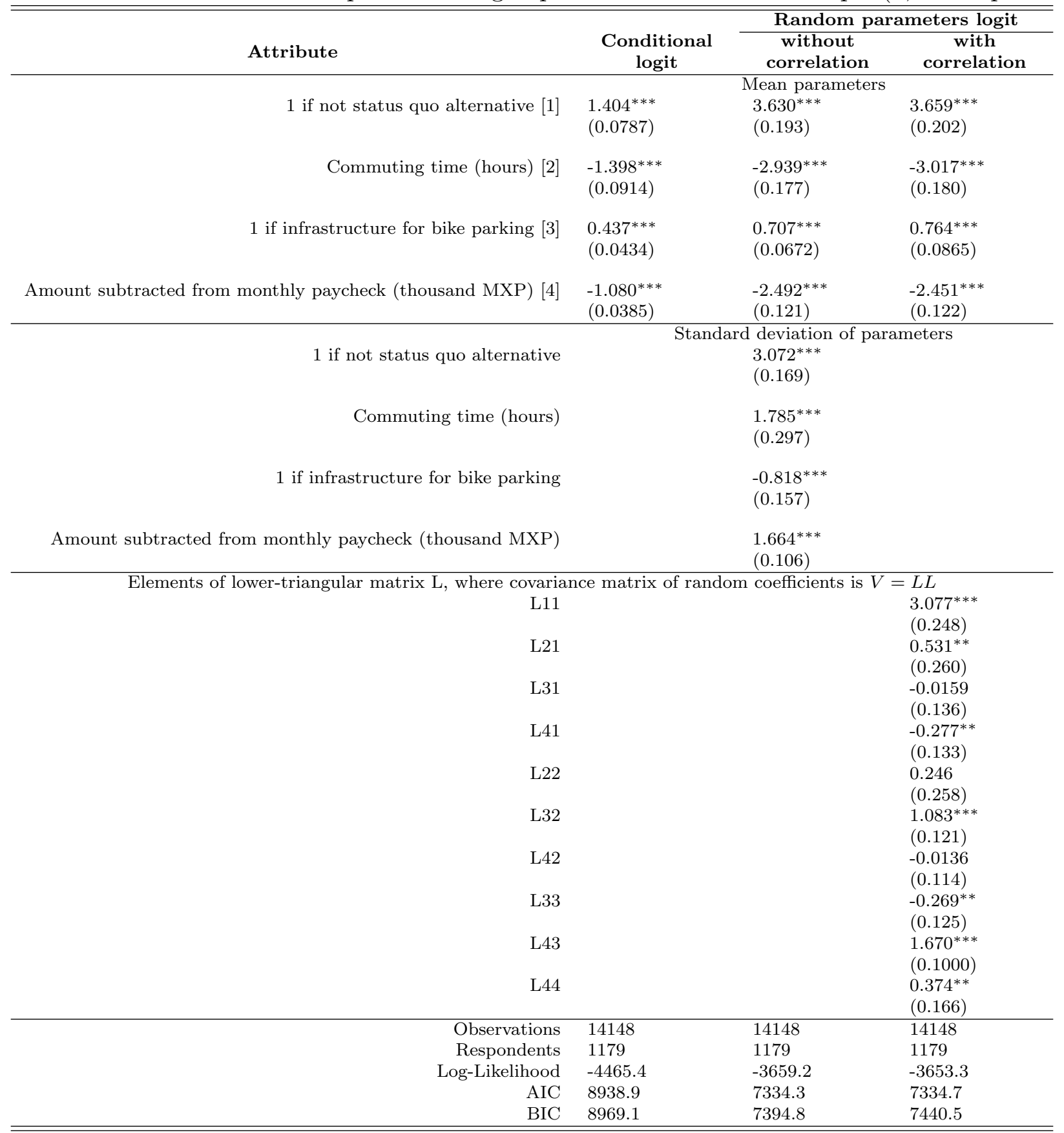

Standard errors in parentheses

${ }^{*} p<0.10,{ }^{* *} p<0.05,{ }^{* * *} p<0.001$ 
Table 4: Willingness to pay (WTP) and 95\% confidence intervals (monthly thousand MXP) resulting from specifications reported in table 3 .

\begin{tabular}{rccc}
\hline \hline \multirow{2}{*}{ WTP for } & Conditional & \multicolumn{2}{c}{ Random parameters logit } \\
\cline { 3 - 4 } & logit & $\begin{array}{c}\text { without } \\
\text { correlation }\end{array}$ & $\begin{array}{c}\text { with } \\
\text { correlation }\end{array}$ \\
\hline not remaining in status quo & 1.3 & 1.46 & 1.49 \\
Lower Bound & 1.18 & 1.33 & 1.36 \\
Upper Bound & 1.42 & 1.58 & 1.63 \\
one our of commuting time & -1.29 & -1.18 & -1.23 \\
Lower Bound & -1.45 & -1.31 & -1.38 \\
Upper Bound & -1.14 & -1.05 & -1.09 \\
bike parking & 0.4 & 0.28 & 0.31 \\
Lower Bound & 0.32 & 0.23 & 0.24 \\
Upper Bound & 0.49 & 0.34 & 0.39 \\
\hline \hline
\end{tabular}

Table 5: Willingness to pay (WTP) and 95\% confidence intervals (monthly thousand MXP) resulting from random parameter logit specifications without correlation reported in tables A1, A2, and A3.

\begin{tabular}{rcccccc}
\hline \hline & \multicolumn{2}{c}{$\begin{array}{c}\text { Income } \\
\text { (MXP) }\end{array}$} & $\begin{array}{c}\text { Commuting time } \\
\text { (minutes) }\end{array}$ & $\begin{array}{c}\text { Total commuting costs } \\
\text { (MXP) }\end{array}$ \\
\hline WTP for & $<\mathbf{1 5 , 0 0 0}$ & $>\mathbf{1 5 , 0 0 0}$ & $<\mathbf{5 0}$ & $>\mathbf{5 0}$ & $<\mathbf{1 0 2 . 6 5}$ & $>\mathbf{1 0 2 . 6 5}$ \\
\hline not remaining in status quo & 1.26 & 1.65 & 1.45 & 1.42 & 1.29 & 1.56 \\
Lower Bound & 1.1 & 1.45 & 1.27 & 1.26 & 1.11 & 1.39 \\
Upper Bound & 1.43 & 1.86 & 1.64 & 1.6 & -48 & -1.05 \\
one our of commuting time & -0.88 & -1.52 & -1.55 & -0.83 & -1.24 & -1.39 \\
Lower Bound & -1.04 & -1.77 & -1.79 & -0.98 & -0.87 & -1.05 \\
Upper Bound & -0.72 & -1.29 & -1.33 & -0.68 & 0.27 & 0.29 \\
bike parking & 0.29 & 0.27 & 0.31 & 0.25 & 0.19 & 0.21 \\
Lower Bound & 0.22 & 0.18 & 0.23 & 0.35 & 0.36 \\
Upper Bound & 0.36 & 0.36 & 0.4 & 0.33 & 0.35 &
\end{tabular}




\section{Figures}

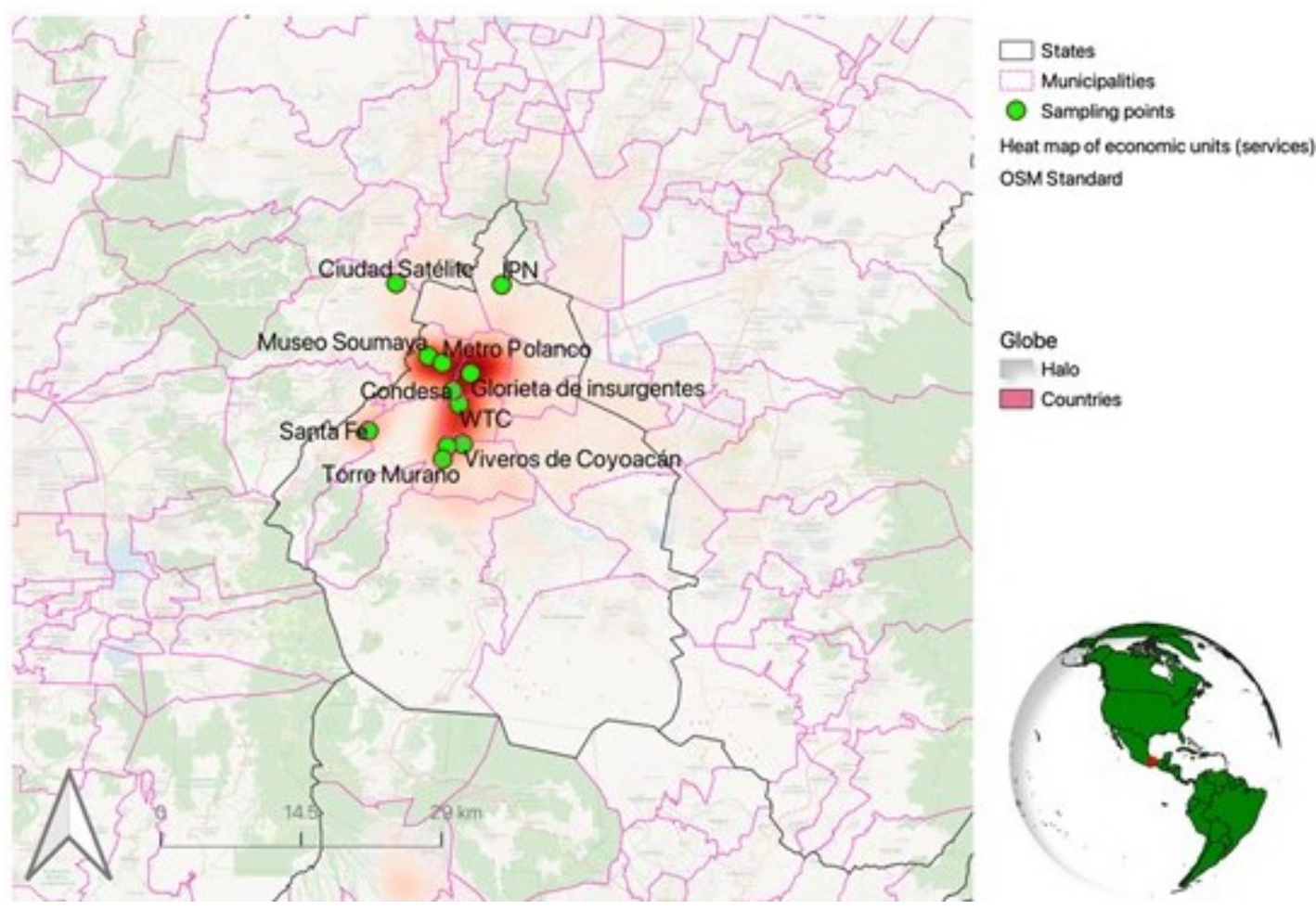

Figure 1: Sampling points and density of office buildings where private and public services are provided in CDMX. 


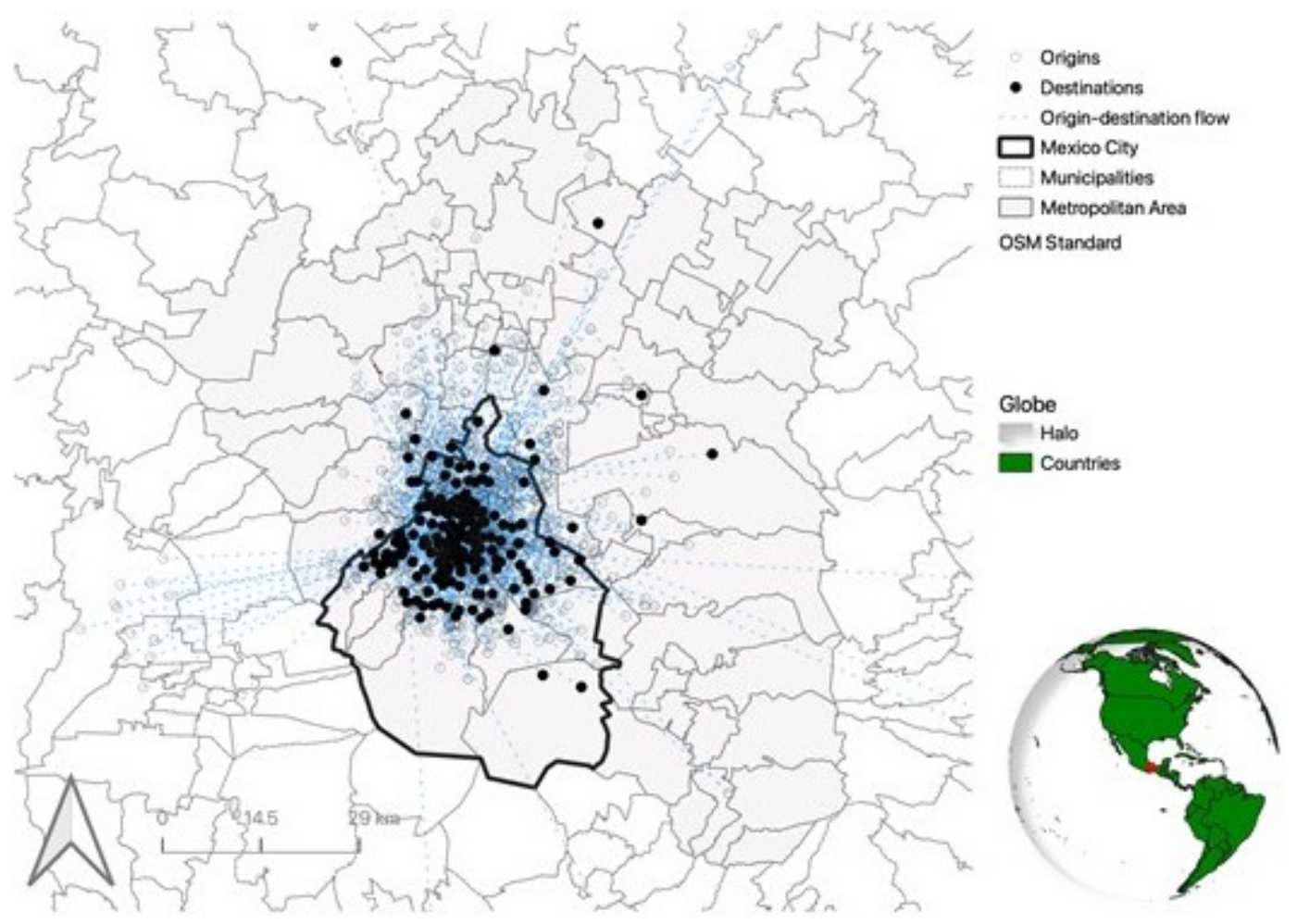

Figure 2: Origin-destination flows documented in this study. 
Elija A, B o C según su preferencia:

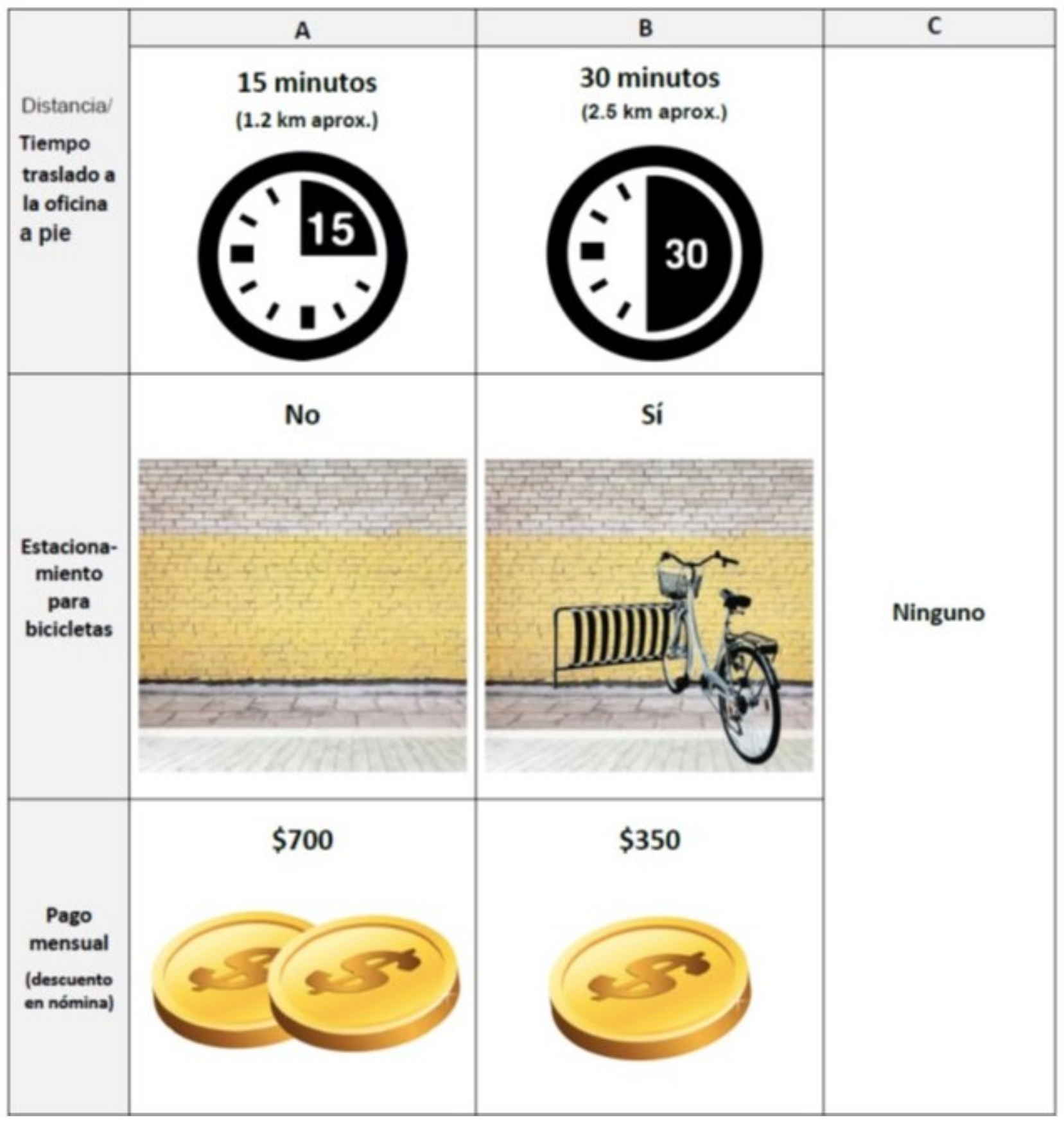

Figure 3: Choice set example. 


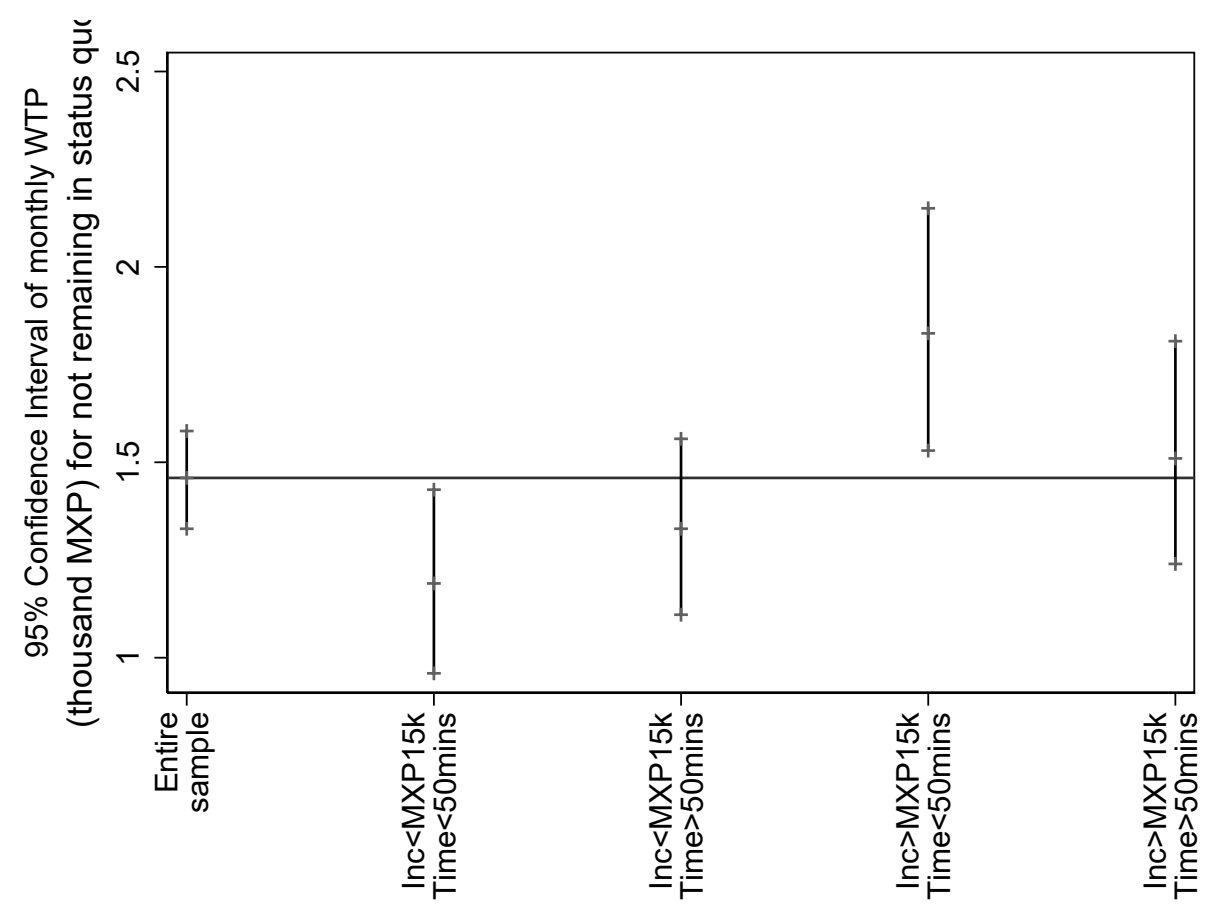

Figure 4: Confidence interval of monthly willingness to pay (thousand MXP) for teleworking alternatives - interaction between income and commuting time.

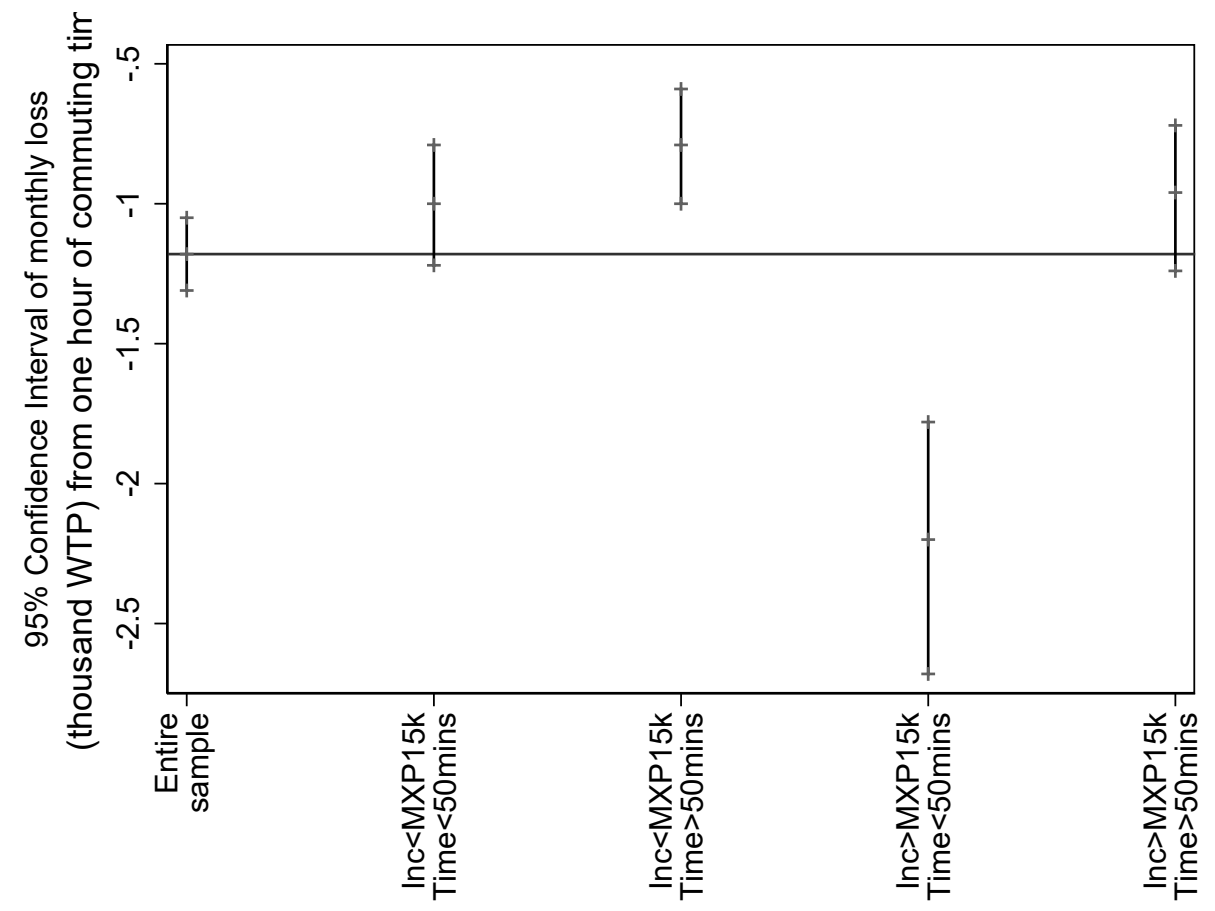

Figure 5: Confidence interval of monthly value (thousand MXP) of one hour of commuting time -interaction between income and commuting time. 


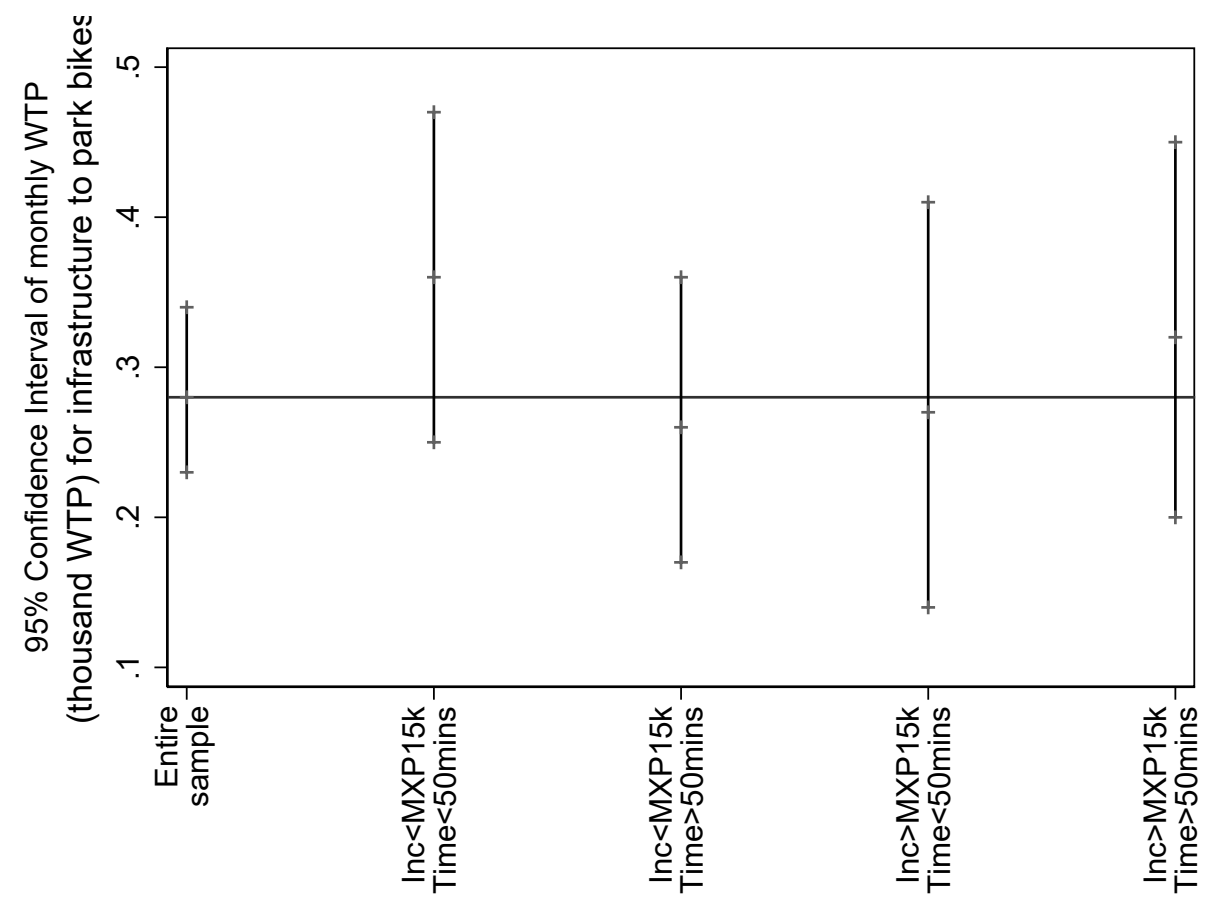

Figure 6: Confidence interval of monthly WTP (thousand MXP) for spaces to park bikes —interaction between income and commuting time. 


\section{Appendix}


Table A1: Conditional and random parameter logit specifications on subsamples defined based on income range

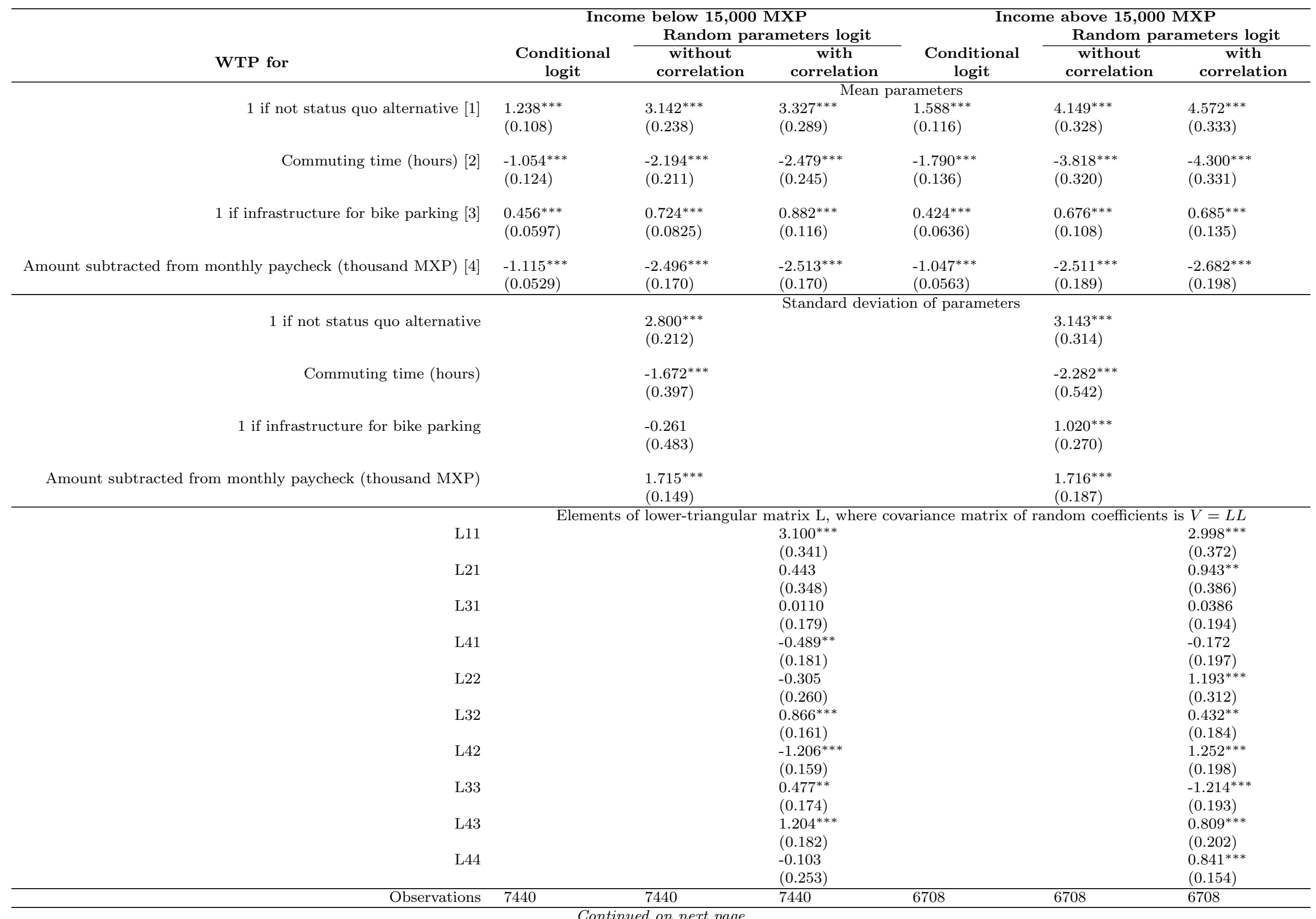


Table A1: Conditional and random parameter logit specifications on subsamples defined based on income range

\begin{tabular}{|c|c|c|c|c|c|c|c|}
\hline \multirow[b]{3}{*}{ WTP for } & & \multicolumn{3}{|c|}{ Income below 15,000 MXP } & \multicolumn{3}{|c|}{ Income above 15,000 MXP } \\
\hline & & \multirow[b]{2}{*}{$\begin{array}{c}\text { Conditional } \\
\text { logit }\end{array}$} & \multicolumn{2}{|c|}{ Random parameters logit } & \multirow[b]{2}{*}{$\begin{array}{c}\begin{array}{c}\text { Conditional } \\
\text { logit }\end{array} \\
\end{array}$} & \multicolumn{2}{|c|}{ Random parameters logit } \\
\hline & & & $\begin{array}{c}\text { without } \\
\text { correlation }\end{array}$ & $\begin{array}{c}\text { with } \\
\text { correlation }\end{array}$ & & $\begin{array}{c}\text { without } \\
\text { correlation }\end{array}$ & $\begin{array}{c}\text { with } \\
\text { correlation }\end{array}$ \\
\hline & Respondents & 620 & 620 & 620 & 559 & 559 & 559 \\
\hline & Log-likelihood & -2343.8 & -1942.0 & -1928.5 & -2110.6 & -1707.5 & -1688.0 \\
\hline & $\mathrm{AIC}$ & 4695.6 & 3899.9 & 3885.1 & 4229.2 & 3430.9 & 3404.1 \\
\hline & $\mathrm{BIC}$ & 4723.3 & 3955.2 & 3981.9 & 4256.5 & 3485.4 & 3499.4 \\
\hline
\end{tabular}

${ }^{*} p<0.10,{ }^{* *} p<0.05,{ }^{* * *} p<0.001$ 
Table A2: Conditional and random parameter logit specifications on subsamples defined based on commuting time

\begin{tabular}{|c|c|c|c|c|c|c|}
\hline \multirow[b]{2}{*}{ WTP for } & \multicolumn{3}{|c|}{$\begin{array}{c}\text { Commuting time below } 50 \text { minutes } \\
\text { Random parameters logit }\end{array}$} & \multicolumn{3}{|c|}{ Commuting time above 50 minutes } \\
\hline & $\begin{array}{c}\text { Conditional } \\
\text { logit }\end{array}$ & \multirow[t]{2}{*}{$\begin{array}{c}\text { without } \\
\text { correlation }\end{array}$} & $\begin{array}{c}\text { with } \\
\text { correlation }\end{array}$ & $\begin{array}{c}\text { Conditional } \\
\text { logit }\end{array}$ & $\begin{array}{c}\text { without } \\
\text { correlation }\end{array}$ & $\begin{array}{c}\text { with } \\
\text { correlation }\end{array}$ \\
\hline & & & Mean & ameters & & \\
\hline 1 if not status quo alternative [1] & $\begin{array}{l}1.420^{* * *} \\
(0.111)\end{array}$ & $\begin{array}{l}3.495^{* * *} \\
(0.265)\end{array}$ & $\begin{array}{l}3.450^{* * *} \\
(0.289)\end{array}$ & $\begin{array}{l}1.416^{* * *} \\
(0.112)\end{array}$ & $\begin{array}{l}3.996^{* * *} \\
(0.294)\end{array}$ & $\begin{array}{l}4.074^{* * *} \\
(0.313)\end{array}$ \\
\hline Commuting time (hours) [2] & $\begin{array}{l}-1.812^{* * *} \\
(0.133)\end{array}$ & $\begin{array}{l}-3.723^{* * *} \\
(0.300)\end{array}$ & $\begin{array}{l}-3.692^{* * *} \\
(0.298)\end{array}$ & $\begin{array}{l}-1.015^{* * *} \\
(0.128)\end{array}$ & $\begin{array}{l}-2.318^{* * *} \\
(0.234)\end{array}$ & $\begin{array}{l}-2.657^{* * *} \\
(0.258)\end{array}$ \\
\hline 1 if infrastructure for bike parking [3] & $\begin{array}{l}0.425^{* * *} \\
(0.0625)\end{array}$ & $\begin{array}{l}0.745^{* * *} \\
(0.0986)\end{array}$ & $\begin{array}{l}0.816^{* * *} \\
(0.132)\end{array}$ & $\begin{array}{l}0.455^{* * *} \\
(0.0609)\end{array}$ & $\begin{array}{l}0.715^{* * *} \\
(0.0999)\end{array}$ & $\begin{array}{l}0.807^{* * *} \\
(0.117)\end{array}$ \\
\hline Amount subtracted from monthly paycheck (thousand MXP) [4] & $\begin{array}{l}-1.031^{* * *} \\
(0.0548)\end{array}$ & $\begin{array}{l}-2.403^{* * *} \\
(0.166)\end{array}$ & $\begin{array}{l}-2.373^{* * *} \\
(0.173)\end{array}$ & $\begin{array}{l}-1.133^{* * *} \\
(0.0543)\end{array}$ & $\begin{array}{l}-2.806^{* * *} \\
(0.192)\end{array}$ & $\begin{array}{l}-2.803^{* * *} \\
(0.200)\end{array}$ \\
\hline \multirow[b]{4}{*}{ Amount subtracted from monthly paycheck (thousand MXP) } & & $\begin{array}{l}3.124^{* * *} \\
(0.235)\end{array}$ & Standard devi & of of parameters & $\begin{array}{l}2.625^{* * *} \\
(0.199)\end{array}$ & \\
\hline & & $\begin{array}{l}1.990^{* * *} \\
(0.395)\end{array}$ & & & $\begin{array}{l}2.036^{* * *} \\
(0.318)\end{array}$ & \\
\hline & & $\begin{array}{l}0.825^{* * *} \\
(0.204)\end{array}$ & & & $\begin{array}{l}1.026^{* * *} \\
(0.199)\end{array}$ & \\
\hline & & $\begin{array}{l}1.525^{* * *} \\
(0.122)\end{array}$ & & & $\begin{array}{l}1.984^{* * *} \\
(0.180)\end{array}$ & \\
\hline \multicolumn{7}{|c|}{ Elements of lower-triangular matrix $\mathrm{L}$, where covariance matrix of random coefficients is $V=L L$} \\
\hline L11 & & & $\begin{array}{l}3.113^{* * *} \\
(0.360)\end{array}$ & & & $\begin{array}{l}3.342^{* * *} \\
(0.397)\end{array}$ \\
\hline $\mathrm{L} 21$ & & & $\begin{array}{l}0.664^{*} \\
(0.385)\end{array}$ & & & $\begin{array}{l}0.263 \\
(0.388)\end{array}$ \\
\hline L31 & & & $\begin{array}{l}-0.0541 \\
(0.204)\end{array}$ & & & $\begin{array}{l}0.0721 \\
(0.192)\end{array}$ \\
\hline L41 & & & $\begin{array}{l}-0.187 \\
(0.199)\end{array}$ & & & $\begin{array}{l}-0.674^{* * *} \\
(0.181)\end{array}$ \\
\hline L22 & & & $\begin{array}{l}0.231 \\
(0.332)\end{array}$ & & & $\begin{array}{l}0.923^{* *} \\
(0.456)\end{array}$ \\
\hline L32 & & & $\begin{array}{l}-1.017^{* * *} \\
(0.168)\end{array}$ & & & $\begin{array}{l}-0.463^{*} \\
(0.251)\end{array}$ \\
\hline L42 & & & $\begin{array}{l}0.902^{* * *} \\
(0.152)\end{array}$ & & & $\begin{array}{l}0.344 \\
(0.279)\end{array}$ \\
\hline L33 & & & $\begin{array}{l}-0.477^{* *} \\
(0.178)\end{array}$ & & & $\begin{array}{l}-1.127^{* * *} \\
(0.164)\end{array}$ \\
\hline L43 & & & $\begin{array}{l}-1.297^{* * *} \\
(0.151)\end{array}$ & & & $\begin{array}{l}0.0336 \\
(0.156)\end{array}$ \\
\hline L44 & & & $\begin{array}{l}-0.114 \\
(0.215)\end{array}$ & & & $\begin{array}{l}1.864^{* * *} \\
(0.164)\end{array}$ \\
\hline Observations & 7272 & 7272 & 7272 & 6876 & 6876 & 6876 \\
\hline
\end{tabular}


Table A2: Conditional and random parameter logit specifications on subsamples defined based on commuting time

\begin{tabular}{|c|c|c|c|c|c|c|c|}
\hline \multirow[b]{2}{*}{ WTP for } & & \multicolumn{3}{|c|}{$\begin{array}{c}\text { Commuting time below } 50 \text { minutes } \\
\text { Random parameters logit }\end{array}$} & \multicolumn{3}{|c|}{$\begin{array}{l}\text { Commuting time above } 50 \text { minutes } \\
\text { Random parameters logit }\end{array}$} \\
\hline & & $\begin{array}{c}\text { Conditional } \\
\text { logit }\end{array}$ & $\begin{array}{c}\text { without } \\
\text { correlation }\end{array}$ & $\begin{array}{c}\text { with } \\
\text { correlation }\end{array}$ & $\begin{array}{c}\text { Conditional } \\
\text { logit }\end{array}$ & $\begin{array}{c}\text { without } \\
\text { correlation }\end{array}$ & $\begin{array}{c}\text { with } \\
\text { correlation }\end{array}$ \\
\hline & Respondents & 606 & 606 & 606 & 573 & 573 & 573 \\
\hline & Log-Likelihood & -2263.0 & -1840.7 & -1835.9 & -2168.1 & -1790.7 & -1782.0 \\
\hline & $\mathrm{AIC}$ & 4533.9 & 3697.4 & 3699.8 & 4344.3 & 3597.3 & 3592.1 \\
\hline & $\mathrm{BIC}$ & 4561.5 & 3752.5 & 3796.3 & 4371.6 & 3652.0 & 3687.8 \\
\hline
\end{tabular}

${ }^{*} p<0.10,{ }^{* *} p<0.05,{ }^{* * *} p<0.001$ 
Table A3: Conditional and random parameter logit specifications on subsamples defined based on total costs of commuting (monetary costs plus opportunity costs)

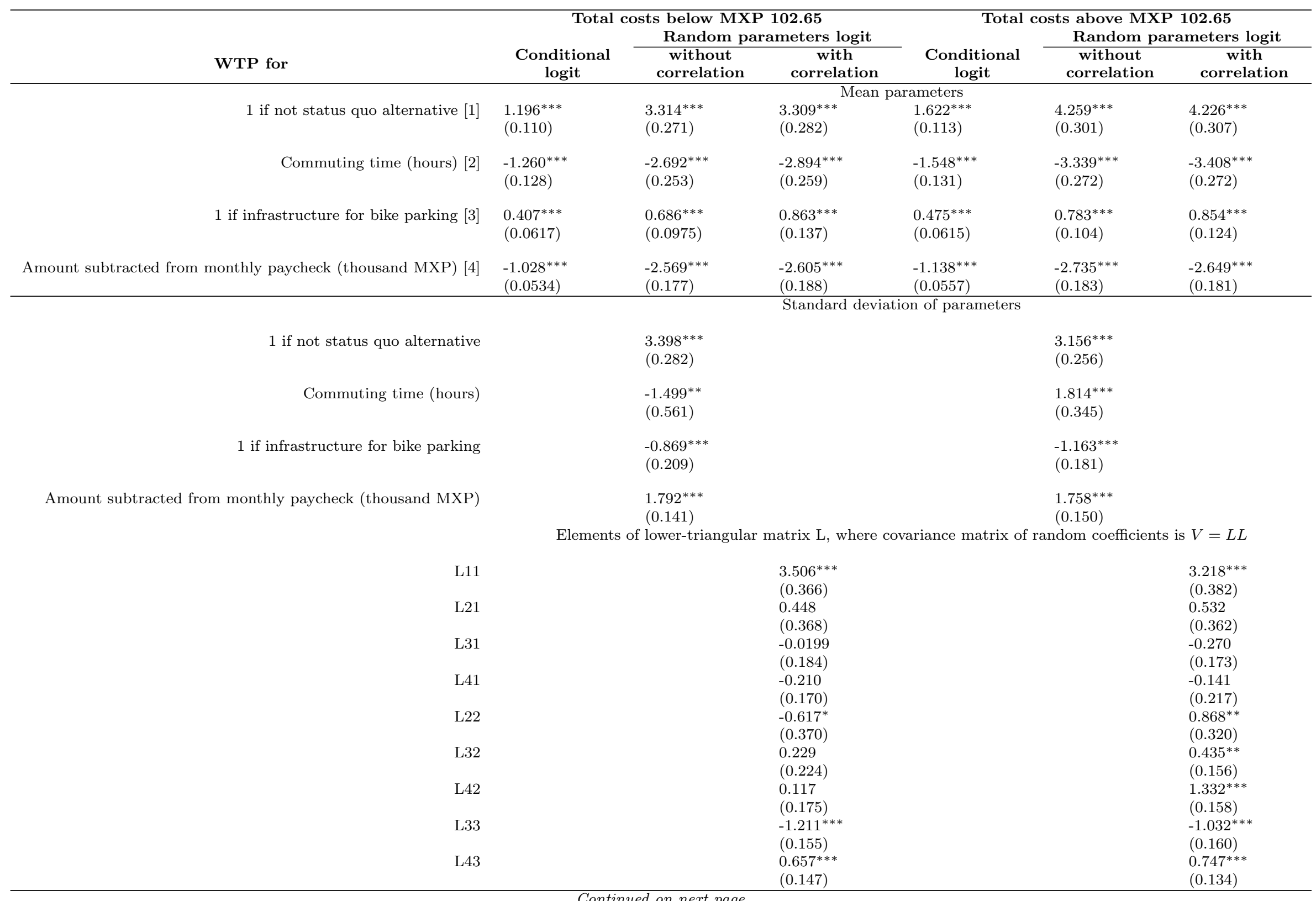


Table A3: Conditional and random parameter logit specifications on subsamples defined based on total costs of commuting (monetary costs plus opportunity costs)

\begin{tabular}{|c|c|c|c|c|c|c|c|}
\hline \multirow[b]{2}{*}{ WTP for } & & \multicolumn{3}{|c|}{ Total costs below MXP 102.65} & \multicolumn{3}{|c|}{ Total costs above MXP 102.65} \\
\hline & & $\begin{array}{c}\text { Conditional } \\
\text { logit }\end{array}$ & $\begin{array}{c}\text { without } \\
\text { correlation }\end{array}$ & $\begin{array}{c}\text { with } \\
\text { correlation }\end{array}$ & $\begin{array}{c}\text { Conditional } \\
\text { logit }\end{array}$ & $\begin{array}{c}\text { without } \\
\text { correlation }\end{array}$ & $\begin{array}{c}\text { with } \\
\text { correlation }\end{array}$ \\
\hline & L44 & & & $\begin{array}{l}1.759^{* * *} \\
(0.146)\end{array}$ & & & $\begin{array}{l}0.625^{* *} \\
(0.199)\end{array}$ \\
\hline & Observations & 7056 & 7056 & 7056 & 7092 & 7092 & 7092 \\
\hline & Respondents & 588 & 588 & 588 & 591 & 591 & 591 \\
\hline & Log-likelihood & -2234.2 & -1808.9 & -1798.2 & -2224.7 & -1825.0 & -1820.2 \\
\hline & $\mathrm{AIC}$ & 4476.4 & 3633.9 & 3624.4 & 4457.4 & 3666.0 & 3668.5 \\
\hline & $\mathrm{BIC}$ & 4503.9 & 3688.8 & 3720.4 & 4484.9 & 3721.0 & 3764.6 \\
\hline
\end{tabular}

${ }^{*} p<0.10,{ }^{* *} p<0.05,{ }^{* * *} p<0.001$ 